\title{
Weakening of Antarctic Stratospheric Planetary Wave Activities in Early Austral Spring Since the Early 2000s: A Response to Sea Surface Temperature Trends
}

\author{
YIHANG HU, WENSHOU TIAN, JIANKAI ZHANG, TAO WANG, MIAN XU \\ Key Laboratory for Semi-Arid Climate Change of the Ministry of Education, College of Atmospheric \\ Sciences, Lanzhou University, China
}

*Correspondence to: wstian@1zu.edu.cn 


\section{Abstract}

Using multiple reanalysis datasets and modeling simulations, the trends of

3 Antarctic stratospheric planetary wave activities in early austral spring since the early

42000 s are investigated in this study. We find that the stratospheric planetary wave

5 activities in September have weakened significantly since 2000, which is related to the

6 weakening of the tropospheric wave sources in the extratropical southern hemisphere.

7 Further analysis indicates that the trend of September sea surface temperature (SST)

8 over $20^{\circ} \mathrm{N}-70^{\circ} \mathrm{S}$ is statistically linked to the weakening of stratospheric planetary wave

9 activities. Numerical simulations support the result that the SST trend in the

10 extratropical southern hemisphere $\left(20^{\circ} \mathrm{S}-70^{\circ} \mathrm{S}\right)$ and the tropics $\left(20^{\circ} \mathrm{N}-20^{\circ} \mathrm{S}\right)$ induce the

11 weakening of wave-1 component of tropospheric geopotential height in the

12 extratropical southern hemisphere, which subsequently leads to the decrease in

13 stratospheric wave flux. The responses of stratospheric wave activities in the southern

14 hemisphere to stratospheric ozone recovery is not significant in simulations. In addition,

15 both reanalysis data and numerical simulations indicate that the Brewer-Dobson

16 circulation (BDC) related to wave activities in the stratosphere has also been weakening

17 in early austral spring since 2000 due to the trend of September SST in the tropics and

18 extratropical southern hemisphere.

19

21 sources; Sea surface temperature 


\section{Introduction}

The stratospheric planetary wave activities have important influences on stratospheric temperature (e.g., Hu \& Fu, 2009; Lin et al., 2009; Li \& Tian, 2017; Li et al., 2018), polar vortex (e.g., Kim et al., 2014; Zhang et al., 2016; Hu et al., 2018) and distribution of chemical substances (e.g., Gabriel et al., 2011; Ialongo et al., 2012; Kravchenko et al., 2011; Zhang et al., 2019a). Meanwhile, the stratospheric circulation modulated by planetary waves can exert impacts on tropospheric weather and climate (e.g., Haigh et al., 2005; Zhang et al., 2019b) through downward control processes (Haynes et al., 1991), which is useful for extended forecast by using preceding signals in the stratosphere (e.g., Baldwin et al., 2001; Wang et al., 2020).

The planetary perturbations generated by large-scale topography, convection and continent-ocean heating contrast can propagate from the troposphere to the stratosphere (Charney \& Drazin, 1961) and form stratospheric planetary waves. As the land-sea thermal contrast in the northern hemisphere is larger than that in the southern hemisphere and produces stronger zonal forcing for the genesis of stratospheric waves, the majority of attention has been given to wave activities and their impacts on weather and climate in the northern hemisphere (e.g., Kim et al., 2014; Zhang et al., 2016; Hu et al., 2018). However, planetary wave activities in the southern hemisphere also play an important role in heating the stratosphere dynamically (e.g., $\mathrm{Hu} \& \mathrm{Fu}, 2009$; Lin et al., 2009), which suppresses Polar Stratospheric Clouds (PSCs) formation and ozone depletion (e.g., Shen et al., 2020a; Tian et al., 2018). The Antarctic sudden stratospheric warming (SSW) that occurred in 2002 (e.g., Baldwin et al., 2003; Nishii \& Nakamura, 
2004; Newman \& Nash, 2005) and 2019 (e.g., Yamazaki el al., 2020; Shen et al., 2020a; Shen et al., 2020b) were associated with significant upward propagation of wave flux. Such episodes are extraordinarily rare in the history, and the one in 2019 contributed to the formation of the smallest Antarctic ozone hole on record (WMO, 2019). In addition, some studies reported that wildfires in Australia at the end of 2019 are related to negative phase of the Southern Annular Mode (SAM), which was induced by the extended influence of the SSW event that occurred in September (Lim et al., 2019; Shen et al., 2020b). In a word, the Antarctic planetary wave activities are important for the stratosphere-troposphere interactions and climate system in the southern hemisphere. Long-term observations in the Antarctic stratosphere show a significant ozone decline from the early 1980 s to the early 2000 s due to anthropogenic emission of chlorofluorocarbons (CFCs) (WMO, 2011) and a recovery signal since 2000s because of phasing out CFCs in response to Montreal Protocal (e.g., Angell and Free, 2009; Krzyścin, 2012; Zhang et al., 2014; Banerjee et al., 2020). The Antarctic stratospheric ozone depletion and recovery have important impacts on climate in the southern hemisphere. The ozone depletion cools the Antarctic stratosphere through reducing absorption of radiation and leads to the strengthening of Antarctic polar vortex during austral spring (e.g., Randel \& Wu, 1999; Solomon et al., 1999; Thompson et al., 2011). The anomalous circulation in the Antarctic stratosphere during austral spring exerts impacts on tropospheric circulations (e.g., intensification of SAM index, poleward shift of tropospheric jet position and expansion of the Hadley cell edge) in the subsequent months (e.g., Thompson et al., 2011; Swart \& Fyfe, 2012; Son et al., 2018; Banerjee et 
67 al., 2020) and influences the distribution of precipitation and dry zone in the southern

68 hemisphere (e.g., Thompson et al., 2011; Barnes et al., 2013; Kang et al., 2011).

69 Following the healing of ozone loss in the Antarctic ozone hole since 2000s (e.g.,

70 Solomon et al., 2016; Susan et al., 2019), great attention has been paid on possible

71 impacts of ozone recovery on climate system in the southern hemisphere (e.g., Son et

72 al., 2008; Barnes et al., 2013; Xia et al., 2020; Banerjee et al., 2020). Son et al. (2008)

73 implemented the Chemistry-Climate Model Validation (CCMVal) models to predict the

74 response of the southern hemisphere westerly jet to stratospheric ozone recovery. Based

75 on the Phase 5 of Coupled Model Intercomparison Projects (CMIP5) models, Barnes et

76 al. (2013) proposed that the tropospheric jet and dry zone edge no longer shift poleward

77 during austral summer since the early 2000s due to ozone recovery. Banerjee et al.

78 (2020) analyzed observations and reanalysis datasets. They found that following the

79 ozone recovery after 2000 , the increase of SAM index and the poleward shifting of

80 tropospheric jet position as well as the Hadley cell edge all experienced a pause. Their

81 results suggest that ozone depletion and recovery have made important contributions to

82 the climate shift that occurred around 2000 in the southern hemisphere.

83 However, some previous studies have reported zonally asymmetric warming

84 patterns in Antarctic stratosphere, which are generated by increased planetary wave

85 activities during austral spring from the early 1980 s to the early 2000 s $(\mathrm{Hu} \& \mathrm{Fu}, 2009$;

86 Lin et al., 2009). Note that the Antarctic stratosphere was experiencing radiative cooling

87 in the same period due to ozone depletion (e.g., Randel \& Wu, 1999; Solomon et al.,

88 1999; Thompson et al., 2011). The increase in stratospheric planetary wave activities 
89 cannot be explained by ozone decline, because the acceleration of stratospheric

90 circumpolar wind caused by radiative cooling induces more wave energy to be reflected

91 back to the troposphere (e.g., Andrews et al., 1987; Holton et al., 2004). Hu \& Fu (2009)

92 attributed the increase in Antarctic stratospheric wave activities to the SST trend from

93 the 1980 s to the 2000 s. Their results indicate that in addition to ozone change, other

94 factors such as SST trend also contribute to climate change in the southern hemisphere.

95 Moreover, the phase of Interdecadal Pacific Oscillation (IPO) also changed at around

962000 (e.g., Trenberth et al., 2013). SST variation influences Rossby wave propagation

97 and tropospheric wave sources, and thereby indirectly affects stratospheric wave

98 activities (e.g., Lin et al., 2012; Hu et al., 2018; Tian et al., 2018). The questions here

99 are: (1) Has the stratospheric planetary wave activity trend in the southern hemisphere

100 been shifting since the 2000s? (2) What are the factors responsible for the trend of

101 Antarctic stratospheric planetary wave activity since the 2000s?

102 In this study, we reveal the trend of Antarctic planetary wave activity in early austral spring since the 2000 s based on multiple reanalysis datasets. We also conduct

104 sensitive experiments forced by linear increments of ozone and SST fields since the

1052000 s to investigate the response of Antarctic planetary activity to above two factors.

106 The remainder of the paper is organized as follows. Section 2 describes the data, 107 methods and configurations of model simulations. Section 3 presents the trends of 108 stratospheric and tropospheric wave activities in early austral spring. Section 4

109 investigates the connections between the trends of SST and stratospheric wave activities.

110 Sections 5 discusses the responses of tropospheric wave source and stratospheric wave 
111 activity to SST trend based on simulations. Major conclusions and discussion are

112 presented in Section 6.

\section{2. Datasets, methods and experimental configurations}

114 a. Datasets

115 In this study, daily and monthly mean data extracted from the Modern-Era

116 Retrospective analysis for Research and Applications Version 2 (MERRA-2;

117 Bosilovich et al., 2015) dataset are used to calculate trends of zonally averaged zonal

118 wind and temperature, BDC, tropospheric wave sources, and the Elisassen-Palm (E-P)

119 flux and its divergence in September. To verify the trend of stratospheric E-P flux, we

120 also refer to the results derived from the European Centre for Medium-range Weather

121 Forecasting (ECMWF) Interim Reanalysis (ERA-Interim; Dee et al., 2011) dataset, the

122 Japanese 55-year Reanalysis (JRA-55; Kobayashi et al., 2015) dataset and the National

123 Centers for Environmental Prediction-Department of Energy Global Reanalysis 2

124 (NCEP-2; Kanamitsu et al., 2002) dataset.

125 SST data are extracted from the Extended Reconstructed Sea Surface Temperature

126 (ERSST) dataset, which is a global monthly mean sea surface temperature dataset

127 derived from the International Comprehensive Ocean-Atmosphere Dataset (ICOADS).

128 The ERSST is on global $2^{\circ} \times 2^{\circ}$ grid and covers the period from January 1854 to the

129 present. We use the newest version (version 5, i.e., v5) dataset to calculate trends and

130 correlations, and produce SST forcing field for model simulations. More details about

131 this version of ERSST can be found in Huang et al. (2017).

132 In addition, the unfiltered Interdecadal Pacific Oscillation (IPO) index derived 
133 from the ERSST v5 dataset is also used in this study. The IPO index is available at

134 https://psl.noaa.gov/data/timeseries/IPOTPI/tpi.timeseries.ersstv5.data and more

135 detailed information about the index can be found in Henley et al. (2015).

136

b. Diagnosis of wave activities and Brewer-Dobson circulation divergence $D_{F}$. Their algorithms are expressed by Eqs. (1)-(3) (Andrews et al., 1987):

$$
F^{(\phi)}=\rho_{0} a \cos \phi\left(\overline{u_{z}} \overline{v^{\prime} \theta^{\prime}} / \overline{\theta_{z}}-\overline{v^{\prime} u^{\prime}}\right)
$$

$$
F^{(z)}=\rho_{0} a \cos \phi\left\{\left[f-(a \cos \phi)^{-1}(\bar{u} \cos \phi)_{\phi}\right] \overline{v^{\prime} \theta^{\prime}} / \overline{\theta_{z}}-\overline{w^{\prime} u^{\prime}}\right\}
$$

where $u, v$ represent zonal and meridional components of horizontal wind, $w$ is

143 vertical velocity, $\theta$ is potential temperature, $a$ is the Earth radius, $f$ is the Coriolis

144 parameter, $z$ is geopotential height, $\phi$ is latitude, $\rho_{0}$ is the background air density.

145 The quasi-geostrophic refractive index (RI) is used to diagnose the environment of wave propagation (Chen \& Robinson, 1992). Its algorithm is written as Equation (4):

$$
R I=\frac{\bar{q}_{\varphi}}{\bar{u}}-\left(\frac{k}{a \cos \varphi}\right)^{2}-\left(\frac{f}{2 N H}\right)^{2}
$$

$$
\bar{q}_{\varphi}=\frac{2 \Omega}{a} \cos \varphi-\frac{1}{a^{2}}\left[\frac{(\bar{u} \cos \varphi)_{\varphi}}{a \cos \varphi}\right]_{\varphi}-\frac{f^{2}}{\rho_{0}}\left(\rho_{0} \frac{\bar{u}_{z}}{N^{2}}\right)_{z}
$$

$150 q, k, N^{2}$ and $\Omega$ are the potential vorticity, zonal wave number, buoyancy

151 frequency, and Earth's angular frequency, respectively.

152 The Brewer-Dobson circulation driven by wave breaking in the stratopause is

153 closely related to stratospheric wave activities. Its meridional and vertical components 
$154\left(\bar{v}^{*}, \bar{w}^{*}\right)$ and stream function $\left(\psi^{*}(p, \phi)\right)$ are expressed by Eqs. (4)-(6) (Andrews et al., 155 1987; Birner \& Bönisch, 2011) :

156

157

158

159

160 objectively. acceleration.

where $p$ is the air pressure, $\pi$ is the circular constant, $g$ is the gravitational

In Eqs. (1)-(8), the overbar and prime denote zonal mean and departure from zonal mean, respectively. The subscripts denote partial derivatives. The Fourier decomposition is used to obtain components of Eqs. (1)-(3) with different zonal wave numbers. Meanwhile, the Fourier decomposed components of geopotential height zonal deviations are also used to determine tropospheric wave sources.

c. Statistical methods

The trend is measured by the slope of linear regression based on the least square estimation. The correlation is used to analyze statistical links between different variables. In this paper, all the time series have been linearly detrended before calculating correlation coefficients $(r)$ and their corresponding significances.

175 We use two-tailed student's $t$ test to calculate the significances of trend, correlation 
176 coefficient or mean difference. The result of significance test is measured by $p$ value or

177 confidence intervals in this paper. $p \leq 0.1, p \leq 0.05$ and $p \leq 0.01$ suggest the trend,

178 correlation coefficient or mean difference is significant at/above the $90 \%, 95 \%$ and $99 \%$

179 confidence levels, respectively. The confidence interval of trend is shown in (7):

$$
\left[\hat{b}-t_{1-\alpha / 2}(n-2) \hat{\sigma}_{b}, \hat{b}+t_{1-\alpha / 2}(n-2) \hat{\sigma}_{b}\right]
$$

181 where $\hat{b}$ is estimated value of slope, $\hat{\sigma}_{b}$ is standard error of slope and it is written

182 as: $\hat{\sigma}_{b}=\hat{b} \cdot \sqrt{\frac{\frac{1}{r^{2}}-1}{n-2}}, t_{1-\alpha / 2}(n-2)$ denotes the value of t-distribution with the degree

183 of freedom equal to $n-2$ and the two-tailed confidence level equal to $1-\alpha$

$184(\alpha=0.90,0.95$ or 0.99$)$. The confidence interval of mean difference is expressed

185 by Eq. (8):

$186\left[\bar{X}-\bar{Y}-t_{1-\alpha / 2}(M+N-2) \cdot S_{w} \cdot \sqrt{\frac{1}{M}+\frac{1}{N}}, \bar{X}-\bar{Y}+t_{1-\alpha / 2}(M+N-2) \cdot S_{w} \cdot \sqrt{\frac{1}{M}+\frac{1}{N}}\right]$

187 where

$$
S_{w}=\sqrt{\frac{1}{M+N-2}\left[\sum_{i=1}^{M}\left(X_{i}-\bar{X}\right)^{2}+\sum_{j=1}^{N}\left(Y_{j}-\bar{Y}\right)^{2}\right]}
$$

189 Here, $\bar{X}$ and $\bar{Y}$ are the sample averages, $M$ and $N$ are the numbers of sample sizes with two populations, $t_{1-\alpha / 2}(M+N-2)$ denotes the value of t-distribution with

191 the degree of freedom equal to $M+N-2$ and the two-tailed confidence level equal 192 to $1-\alpha$.

194 spatial dependence (e.g. Xie et al., 2020). To find out a robust relationship between the trend of SST in a specific region and the trend of stratospheric wave activities, we divide 
196 the global ocean into three regions: SH (the extratropical southern hemisphere, $70^{\circ} \mathrm{S}-$

$19720^{\circ} \mathrm{S}$ ), TROP (the tropics, $20^{\circ} \mathrm{S}-20^{\circ} \mathrm{N}$ ) and $\mathrm{NH}$ (the extratropical northern hemisphere,

$\left.19820^{\circ} \mathrm{N}-70^{\circ} \mathrm{N}\right)$. Since the impacts in different regions might be combined, we also

199 consider three combined regions named as SHtrop (the extratropical southern

200 hemisphere and the tropics, $70^{\circ} \mathrm{S}-20^{\circ} \mathrm{N}$ ), $\mathrm{NH}$ trop (the extratropical northern hemisphere

201 and the tropics, $\left.20^{\circ} \mathrm{S}-70^{\circ} \mathrm{N}\right)$ and the Globe $\left(70^{\circ} \mathrm{S}-70^{\circ} \mathrm{N}\right)$. To find statistical connections

202 between the trend of SST and that of stratospheric wave activities, we examine the first

203 three leading patterns (EOF1, EOF2, EOF3) and principal components (PC1, PC2, PC3)

204 of SST in above six regions obtained from Empirical Orthogonal Function (EOF)

205 analysis. In all the six regions, there is always one EOF modes that shows great

206 similarity to the spatial pattern of trend (not shown) as we do not detrend SST time

207 series when the EOF analysis is carried out. Thus, the significance of the correlation

208 between the PC time series of that EOF mode and time series of stratospheric E-P flux

209 can be used as the criterion to determine the statistical connection between the trend of

210 SST and the trend of stratospheric wave activities.

211 d. The model and experiment configurations

212 The FWSC component in the Community Earth System Model (CESM; version

213 1.2.0) is used to verify the impact of SST and ozone recovery trends on tropospheric

214 wave sources and stratospheric wave activities in early austral spring. The FWSC

215 component is the Whole Atmosphere Community Climate Model version 4 (WACCM4)

216 with specified chemistry forcing fields (such as ozone, greenhouse gases (GHG),

217 aerosols and so on), which have fixed values in 2000 by default. The WACCM4 
218 includes active atmosphere, data ocean (run as a prescribed component, simply reading

219 SST forcing data instead of running ocean model), land and sea ice. Important physics

220 schemes in the WACCM4 are based on those in the Community Atmospheric Model

221 version 4 (CAM4; Neale et al., 2013). The WACCM4 uses a finite-volume dynamic

222 framework and extends from the ground to approximately $145 \mathrm{~km}\left(5.1 \times 10^{-6} \mathrm{hPa}\right)$

223 altitude in the vertical with 66 vertical levels. The simulations presented in this paper

224 are conducted at a horizontal resolution of $1.9^{\circ} \times 2.5^{\circ}$. More information about the

225 WACCM can be found in Marsh et al. (2013).

Control experiments and sensitive experiments are conducted to investigate responses of Antarctic stratospheric wave activities to SST trend and the ozone recovery

228 trend in early austral spring. For the experiments of SST trends, monthly mean global

229 SST during 1980-2000 derived from the ERSST v5 dataset is used as SST forcing field

230 in the control experiment (sstctrl). For the four sensitive experiments (sstNH, sstSH,

231 ssttrop, sstSHtrop), linear increments of SST in different regions in September during

232 2000-2017 are used as the forcing field. Ozone, aerosols and greenhouse gases (GHG)

233 in the control experiment and the four sensitive experiments all have the fixed values

234 in 2000. For the experiments of ozone recovery trend, monthly mean three-dimensional

235 global ozone during 1980-2000 derived from the MERRA-2 dataset is used as the ozone

236 forcing field in the control experiment (O3ctrl). The sensitive experiment (O3sen) is

237 forced by linear increments of ozone in September during 2001-2017. The SSTs in

238 O3ctrl and O3sen both are monthly mean global SST during 1980-2000. The aerosol

239 and greenhouse gases values in 2000 are used. These experiment configurations are 
summarized and listed in Table 1 and Table 2.

241 First, we run the FWSC component to generate randomly different initial

242 conditions for 120 years with free run. Then, each experiment includes 100 ensemble

243 members that run from July to September forced by these initial conditions from the

24421 st year to the 120th year in July. The forcing fields of SST and ozone are only

245 superposed from July to September. July and August are taken as spin-up time and

246 simulations during this period are discarded. The ensemble mean in September derived

247 from these 100 ensemble members is regarded as the final result of each experiment. A

248 similar approach is implemented for sensitive experiments, in which the forcing fields

249 superposed only in certain months. The same approach has been used in previous

250 studies (e.g., Zhang et al., 2018).

\section{3. Trend of planetary wave activities in early austral spring}

Figure 1 shows the trends of stratospheric planetary wave activities in the southern hemisphere September during 1980-2000 and 2000-2017, respectively. Note that the vertical E-P flux entering into the stratosphere over $50^{\circ} \mathrm{S}-70^{\circ} \mathrm{S}$ in September has been increasing during 1980-2000, accompanied by intensified wave flux convergence in the upper stratosphere (Fig. 1a) that is mainly contributed by the wave-1 component (Fig. 1b). This feature implies that the stratospheric planetary wave activities have strengthened in early austral spring during 1980-2000. A similar result has been

259 reported in previous studies ( $\mathrm{Hu} \& \mathrm{Fu}, 2009$; Lin et al., 2009). During 2000-2017,

260 however, vertical transport of stratospheric E-P flux weakened over the subpolar region 261 of the southern hemisphere, which was accompanied by intensified wave flux 
262 divergence in the upper stratosphere (Fig. 1d) mainly contributed by the wave-1

263 component (Fig. 1e) while the wave-2 component also made certain contributions (Fig.

264 1f). Similar features also appear in August, but not as significant as that in September

265 (Fig. S1). For this reason, hereafter we focus on the features in September.

266 The SSW that occurred in 2002 was accompanied with large upward wave fluxes

267 in the stratosphere, which is extremely rare in history and has been studied in numerous

268 previous studies (e.g., Baldwin et al., 2003; Nishii \& Nakamura, 2004; Newman \&

269 Nash, 2005). Since the period with a negative trend of stratospheric vertical wave flux

270 is short, it is necessary to further investigate whether such a negative trend is artificially

271 influenced by the single year of 2002. Therefore, following Banerjee et al. (2020), we

272 use a change-point method to test the significance of the trend during various periods

273 based on four reanalysis datasets (ERA-Interim, MERRA-2, JRA-55, NCEP-2).

274 Figures 2a (including the year 2002) and 2b (excluding the year 2002) display the time

275 series $(\mathrm{Fz})$ of area-weighted vertical stratospheric wave flux over the southern

276 hemisphere subpolar region obtained from different reanalysis datasets. Note that the

277 wave flux time series obtained from the four reanalysis datasets all present a positive

278 trend from the early 1980 s to the early 2000 s and a negative trend from the early 2000 s

279 to present, regardless of whether the extreme value in 2002 is removed or not. The

280 correlation coefficients of the time series between these reanalysis datasets are above

2810.9 and statistically significant (Table 3), suggesting that the time series derived from

282 different datasets are consistent with each other. Figures $2 \mathrm{c}-\mathrm{f}$ show the trends and

283 corresponding confidence intervals calculated with four different beginning years (1980, 
$1981,1982,1983)$, four different ending years $(2015,2016,2017,2018)$, and change-

285 point years from 1998 to 2013 . The trends and confidence intervals in Figures $2 \mathrm{~g}-\mathrm{j}$ are

286 the same as that in Figures 2c-f, except that the extreme value in 2002 is removed. The positive trend from the early 1980 s to the 21 st century remains significant regardless of different beginning years and ending change-point years (Figs. 2c-j). However, Figures 2c-f and Figures $2 \mathrm{~g}-\mathrm{j}$ indicate that the positive value of the trend is decreasing gradually when the period is prolonged, which is apparently attributed to the negative trend with the beginning change-point year of around 2000. Although the negative trend from the change-point year to ending year becomes less significant when the value in 2002 is removed, it remains significant in some periods, which are also illustrated on diagrams

294 of latitude-pressure profiles (Fig. S2). Therefore, the weakening of stratospheric wave

295 activities in early austral spring since the early 2000s is robust. In this paper, we take the year 2000 as the beginning year of the weakening trend to simplify descriptions in the following discussion.

Figure 3 shows the trends of tropospheric wave sources in September since 2000.

299 There is a significant positive trend of the wave- 1 component in $500 \mathrm{hPa}$ geopotential height over the southern Indian ocean and a significant negative trend over the southern Pacific, which form an out-of-phase superposition on its climatology (Fig. 3b). The trend pattern of wave- 2 component is also out-of-phase with its climatology, although

303 it is not significant (Fig. 3c). The above features still maintain when the values in 2002

304 are removed (Fig. S3b, c), implying that the southern hemispheric tropospheric wave sources in early austral spring have weakened since 2000 , which is also reflected in the 
306 decrease of tropospheric vertical wave flux (Fig. 3d, e; Fig. S3d, e).

307 4. Role of SST trends in the weakening of Antarctic stratospheric wave activities

In this section, we further explore factors that lead to the weakening of tropospheric wave sources and stratospheric wave activities since the early 2000s in

311 early austral spring. Numerous studies reported that the variations in sea surface 312 temperature can affect stratospheric climate (e.g., Li, 2009; Hurwitz et al., 2011; Lin et 313 al., 2012; Hu et al., 2014; Hu et al., 2018; Tian et al., 2018; Xie et al., 2020). Hu \& Fu 314 (2009) also attributed the strengthened stratospheric wave activities in the southern

315 hemisphere to SST trend from the early 1980s to the early 2000s. Furthermore, global

316 SST in September during 2000-2017 also has a significant trend. The significant

317 warming pattern is mainly found over the southern Indian ocean, the southern Atlantic ocean, the eastern and western equatorial Pacific, the western equatorial and Northern

319 Atlantic ocean (Fig. 4b). A significant cooling pattern is located over the southeast

320 Pacific (Fig. 4b). In a word, the spatial pattern of SST trend during 2000-2017 is

321 obviously different from that during 1980-2000 (Fig. 4a, b). Thus, it is necessary to

322 analyze the connection between SST trend and wave activity trend since the early 2000s.

323 Figure 5 shows the significance of principle component (PC) trends (Figs. 5a-f) of

324 SST in different regions, and the significance of correlations (Figs. 5g-l) between the

325 PC time series and Fz during various periods in September. The trend of PC1 time series

326 in SH region is significant during serval periods (Fig. 5a), while the correlation between

327 PC1 and Fz is only significant with the particular ending year of 2015 (Fig. 5g). This 
328 feature suggests that the connection between the SST trend in SH region and the trend 329 of stratospheric wave activity is not robust. The correlation between trend of

330 stratospheric wave activity and that of SST in TROP or NH region is also weak (Fig.

$3315 \mathrm{e}, \mathrm{f})$. As for the combined regions, note that the PC2 time series in SHtrop region has

332 a significant trend (Fig. 5d) and the correlation between the PC2 time series in SHtrop

333 and Fz with the beginning year of around 2000 is also significant (Fig. 5j) regardless of

334 different ending years. This feature implies that the extratropical southern hemisphere

335 and tropical SST has a robust connection with stratospheric wave activities in early

336 austral spring since the early 2000s. The correlations between Fz and all PC time series

337 in NHtrop (Fig. 5k) and Globe (Fig. 5l) region are not as robust as that between Fz and

338 PC2 time series in SHtrop region (Fig. 5j), indicating that the connection between SST

339 trend in extratropical northern hemisphere and the trend of stratospheric wave activity

340 is weak.

341 Figure 6 shows the first three EOF modes of September SST in SHtrop region 342 during 2000-2017. The second mode (Fig. 6b) shows a great similarity to the spatial 343 pattern of SST trend (Fig. 4b), and the corresponding PC2 time series also has a 344 significant trend (slope $=1.71, \mathrm{p}<0.01$ ). The correlation between PC2 and the Fz is 345 significant $(\mathrm{r}=-0.56, \mathrm{p}=0.016)$ and the correlation coefficient remains significant $(\mathrm{r}=$ $3460.46, \mathrm{p}=0.065$ ) at the $90 \%$ confidence level when the value in 2002 is removed. This 347 result suggests that the SST trend in SHtrop region is closely related to the recent 348 weakening of stratospheric wave activities. The first EOF mode is similar to IPO (Fig. 349 6a) and its corresponding principal component is highly significantly correlated ( $\mathrm{r}=-$ 
$350 \quad 0.98, \mathrm{p}<0.01$ ) with the unfiltered IPO index. However, it shows no significant trend (Fig.

351 6d) and has no significant correlation (Fig. 6g) with stratospheric wave flux, implying that the linkage between the IPO phase change at around 2000 (e.g. Trenberth et al., 2013) and the weakening of Antarctic stratospheric wave activities is weak. The correlation between PC3 and Fz is also not significant (Fig. 6i). Therefore, it is possible that the combined effect of SST trend (the second EOF mode) in the tropical and extratropical southern hemisphere leads to the weakening of stratospheric wave activities in early austral spring since the early 2000s.

\section{Simulated changes in Antarctic stratospheric wave activities forced} contribute to the weakening of the southern hemispheric stratospheric wave activities. increments of SST in September during 2000-2017 (Fig. 7; more details can be found in Section 2) are conducted to verify the results discussed in Section 4. 
372 patterns in an out-of-phase style (Figs. 8e, f, h, i, k, l), indicating that the SST trends in

373 SH, TROP and SHtrop lead to a weakening of tropospheric wave sources in the

374 extratropical southern hemisphere. However, the $500 \mathrm{hPa}$ geopotential height anomaly

375 of the predominate wave-1 component in the extratropical southern hemisphere forced

376 by the experiment with NH SST change is relatively weak (Fig. 8b). This feature

377 suggests that the SST trend in extratropical northern hemisphere is incapable of

378 inducing a robust response of tropospheric wave sources in the extratropical southern

379 hemisphere.

380 Figure 9 shows the simulated responses of stratospheric wave activities in the

381 southern hemisphere to SST changes in different regions. It is found that the

382 experiments with SST changes in SH, TROP and SHtrop show significantly weakened

383 stratospheric wave activities (Figs. 9d, g, j), which are mainly attributed to the responses

384 of the wave- 1 component (Figs. 9e, h, k). These results are consistent with the responses

385 of tropospheric wave sources (Figs. 8d, e, g, h, j, k). However, there are no significant

386 anomalies of stratospheric wave flux in the subpolar region as exhibited in Figures 9a

387 and $9 \mathrm{~b}$, which is consistent with the response of corresponding tropospheric wave

388 sources (Fig. 8a, b) and the weak correlation between Fz and PC time series of SST in

389 NH region (Fig. 5i). It suggests that the response of southern hemisphere stratospheric

390 wave activities to SST trend in NH region is weak.

391 Results of all these experiments are summarized and displayed in Figure 10, which

392 is quantified by the frequency distribution of southern hemisphere stratospheric vertical

393 wave flux derived from the 100 ensemble members of each experiment. Compared to 
394 the blue fitting curves, the red fitting curves shift to the left as shown in Figs. 10b, 10c

395 and 10d, suggesting that the SST changes in SH, TROP and SHtrop regions weaken the upward propagation of stratospheric wave flux. The area-weighted anomalies of vertical E-P flux in the subpolar region of the southern hemisphere induced by SST changes in SH, TROP and SHtrop regions are $-0.084 \times 10^{5} \mathrm{~kg} \cdot \mathrm{s}^{-2},-0.12 \times 10^{5} \mathrm{~kg} \cdot \mathrm{s}^{-2}$ and $-0.13 \times 10^{5} \mathrm{~kg} \cdot \mathrm{s}^{-2}$, respectively. The sum of the anomalies forced by sstSH and ssttrop is not equal to the anomaly forced by sstSHtrop, which may be resulted from non-linear interactions between the responses of wave activities to SST trends in SH region and TROP region. The weakening of stratospheric wave activities forced by SST increment in the tropical region is more obvious and more significant than that in extratropical southern hemisphere (Figs. 10b, c, e), implying that the SST trend in the tropical region

405 contributes more to the weakening of stratospheric wave activities since 2000. Meanwhile, it is apparent that the weakening of the southern hemisphere stratospheric wave activities forced by sstSHtrop is the most significant among all the sensitive experiments (Fig. 10e). The reduction of vertical E-P flux over $\left(50^{\circ} \mathrm{S}-70^{\circ} \mathrm{S}, 200 \mathrm{hPa}-\right.$ $10 \mathrm{hPa}$ ) forced by sstSHtrop is approximately $12 \%$. These simulation results indicate that the weakening of the Antarctic stratospheric wave activities in September since 2000 is induced by the combined effects of SST trends in the tropical and extratropical

412 southern hemisphere. It also explains why the independent correlation between Fz and

413 PC obtained for $\mathrm{SH}$ or TROP region is not as significant as that between $\mathrm{Fz}$ and PC

414 obtained for SHtrop region (Figs. 5g, h, j). Moreover, the mean linear increment of area415 weighted vertical E-P flux from $200 \mathrm{hPa}$ to $10 \mathrm{hPa}$ over $70^{\circ} \mathrm{S}-50^{\circ} \mathrm{S}$ in September during 
$4162000-2017$ derived from four reanalysis datasets is about $-0.38 \times 10^{5} \mathrm{~kg} \cdot \mathrm{s}^{-2}$. Therefore,

417 the contribution of SST trend over $20^{\circ} \mathrm{N}-70^{\circ} \mathrm{S}$ (the SHtrop region) to the weakening of

418 stratospheric activities is approximately $34 \%$.

\section{6. Conclusions and Discussion}

This study analyzes the trend of Antarctic stratospheric planetary wave activities in early austral spring since the early 2000s based on various reanalysis datasets. Using the change-point method, we find that the Antarctic stratospheric wave activities in September have been weakening significantly since 2000 , which means the intensified trend of wave activities noted in previous researches ( $\mathrm{Hu} \& \mathrm{Fu}, 2009$; Lin et al., 2009)

425 are reversed after 2000 in early austral spring. Further analysis suggests that the

426 weakening of stratospheric wave activities is related to the weakening of tropospheric

427 wave sources in extratropical Southern Hemisphere, which is mainly contributed by the

428 wave-1 component. Moreover, EOF analysis and correlation analysis indicate that the 429 stratospheric wave activities in early austral spring during 2000-2017 are related to PC2 430 of SST over $20^{\circ} \mathrm{N}-70^{\circ} \mathrm{S}$ (i.e., the SHtrop region). The corresponding EOF2 mode also

431 shows a great similarity to the spatial pattern of SST trend, suggesting that the 432 weakening of stratospheric wave activities is connected to the trend of SST in SHtrop region. Meanwhile, the linkage between the SST trend in NH region and the weakening

434 of stratospheric wave activities is weak. Finally, the model simulations support the 435 conclusion that the SST changes in SHtrop region lead to the weakening of tropospheric 436 wave sources and stratospheric wave activities. The contribution of SST trend in tropical region to the weakening of stratospheric wave activities is larger than that in 
438 the extratropical southern hemisphere. However, the response of tropospheric wave

439 sources and stratospheric wave activities to SST trend in NH region is not significant.

440 The contribution of SST trend over SHtrop region to the weakening of stratospheric

441 wave activities is about $34 \%$.

442 The question that remains answered is whether the ozone recovery trend also 443 contributes to the weakening of stratospheric wave activities in September since the 444 early 2000s. As described in Section 2, a control experiment (O3ctrl) forced by 445 climatological ozone and a sensitive experiment forced by the linear increment of 446 global ozone in September during 2001-2017 are conducted to address the above 447 question. The pattern of ozone forcing field is similar to its trend pattern (Figs. S4c, d;

448 Fig. S5). We choose the period of 2001-2017 because we notice that the ozone recovery 449 trend derived from MERRA-2 in September with the beginning year of 2000 is not significant (Fig. S4a, b). Meanwhile, as the SSW in 2002 induces poleward transport of large amounts of ozone, the data in 2002 are removed when linear increments are calculated. Other details about these two experiments have been given in Section 2 and Table 2. The simulated results indicate that there is no significant response of wave flux (Fig. 11a, d) as well as its Fourier decomposed components (Fig. 11b, c) over southern

455 hemisphere subpolar region in the stratosphere, suggesting that the prescribed ozone 456 recovery is incapable of inducing the weakening of stratospheric wave activities.

457 Many researchers claimed that the climate transition around 2000 in the southern 458 hemisphere is related to ozone depletion and recovery (e.g., Barnes et al., 2013; 
460 previous studies. Firstly, the southern hemisphere tropospheric circulation (i.e., the

461 SAM index, the tropospheric jet position and the Hadley cell edge) transition related to ozone depletion and recovery reported in these previous studies basically occurred in austral summer (e.g., Son et al., 2008; Thompson et al., 2011; Barnes et al., 2013; Banerjee et al., 2020). These tropospheric circulation transitions are induced by downward coupling of circulation anomalies in the stratosphere (e.g., Thompson et al., 2011) during October and November, when solar radiation covers the entire Antarctic and causes radiative heating effects. However, we focus on September in the present study. The Antarctic stratospheric circulation response to ozone variation in September is not as strong as that in October or November (e.g., Thompson et al., 2011, Fig. 1b, d)

470 because solar radiation can only reach part of the Antarctic stratosphere during a majority period of September. This fact implies that the response of wave propagation environment in the Antarctic stratosphere to ozone trend is also not significant (Fig. S6). Secondly, the FWSC component used in this study is an atmospheric module with prescribed SST and gases. Therefore, the model results only indicate that the weakening of stratospheric wave activities can be attributed to SST trends, while the impact of ozone depletion and recovery trend in the tropics and mid-latitudes on the shift of SST trend pattern cannot be determined based on the model simulations. This is an issue

478 beyond the scope of this study and further investigation is necessary using a fully

479 coupled earth system model. 
482 spring during 2000-2017 (Fig. 12b), which is contrary to the intensified trend during

483 1980-2000 (Fig. 12a). The transition of BDC around 2000 is believed to be associated

484 with ozone depletion and recovery (e.g., Polvani et al., 2017; Polvani et al., 2018).

485 However, our modeling results suggest that the SST trend is responsible for the

486 weakening of BDC in September since 2000 (Fig. 12d, e, f), The response of BDC to

487 ozone recovery is not significant (Fig. 12c), especially for the branch near the Antarctic.

488 These results indicate that the SST trend should be taken into consideration when

489 exploring the mechanism for the climate transition in the southern hemispheric

490 stratosphere around 2000.

491

492 Acknowledgements:

493 This work is supported by the National Natural Science Foundation of China 494 (41630421 and 42075062). We thank Institute Pierre Simon Laplace (IPSL), NCEP and 495 NCAR, National Aeronautics and Space Administration (NASA) and Japan 496 Meteorological Agency (JMA) for providing ERA-Interim, NCEP-2, MERRA-2 and 497 JRA-55 datasets. We thank National Oceanic and Atmospheric Administration (NOAA) 498 for providing ERSST v5 dataset and IPO index. We also thank the scientific team at 499 NCAR for providing CESM-1 model. Finally, we thank the computing support 500 provided by the College of Atmospheric Sciences, Lanzhou University.

503 Andrews, D. G., Holton, J. R., \& Leovy, C. B.: Middle atmosphere dynamics, (p. 489), San Diego, 

https://doi.org/10.1029/2008JD010860, 2009. https://doi.org/10.1126/science.1063315, 2001. stratospheric warming in the Southern Hemisphere in 2002: Dynamical aspects of the lowermost stratosphere, Atmos. Chem. Phys., 11(2), 817-827, https://doi.org/10.5194/acp11-817-2011, 2011.

Barnes, E. A., Barnes, N. W., Polvani, L. M.: Delayed southern hemisphere climate change induced by stratospheric ozone recovery, as projected by the cmip5 models, J. Climate, 27(2), 852867, https://doi.org/10.1175/JCLI-D-13-00246.1, 2014

Bosilovich, M., Akella, S., Coy, L., Cullather, R., Draper, C., Gelaro, R. and Suarez, M.: MERRA-2: Initial Evaluation of the Climate, NASA Technical Report Series on Global Modeling and Data Assimilation, 43, 139, 2015.

Banerjee, A., Fyfe, J. C., Polvani, L. M., Waugh D., Chang K. L.: A pause in Southern Hemisphere 
Charney, J. G., \& Drazin, P. G.: Propagation of planetary-scale disturbances from the lower into the https://doi.org/10.1029/JZ066i001p00083, 1961.

Dee, D. P., Uppala, S. M., Simmons, A. J., Berrisford, P., Poli, P., Kobayashi, S., et al.: The ERAInterim reanalysis: Configuration and performance of the data assimilation system, Q. J. Roy. Meteor. Soc., 137(656), 553-597, https://doi.org/10.1002/qj.828, 2011. and depleted stratospheric ozone using a stratosphere-resolving coupled GCM, Q. J. Roy. Meteor. Soc., 129(589), 947-966, https://doi.org/10.1256/qj.02.102, 2003.

Garcia, R. R., \& Randel, W. J.: Acceleration of the brewer-dobson circulation due to increases in

gases, J.

Atmos.

Sci., 65(8),

2731-2739. https://doi.org/10.1175/2008JAS2712.1, 2008. atmospheric ozone and water vapour derived from odin satellite data 2001-2010, Atmos. 0469(1991)048<0651:OTCOED>2.0.CO;2, 1991.

Haigh, J. D., Blackburn, M., \& Day, R.: The response of tropospheric circulation to perturbations in 

https://doi.org/10.1175/JCLI3472.1, 2005.

550 Holton, J.: An introduction to dynamic meteorology, Academic Pr., 2004.

551

552

Hu, Y., \& Fu, Q.: Stratospheric warming in southern hemisphere high latitudes since 1979, Atmos. Chem. Phys., 9(13), 4329-4340, https://doi.org/10.5194/acp-9-4329-2009, 2009.

Hurwitz, M. M., Newman, P. A., Oman, L. D., \& Molod, A. M.: Response of the antarctic stratosphere to two types of El niño events, J. Atmos. Sci., 68(4), 812-822. https://doi.org/10.1175/2011JAS3606.1, 2011.

Haarsma, R. J., \& Selten, F.: Anthropogenic changes in the Walker circulation and their impact on the extra-tropical planetary wavestructure in the Northern Hemisphere, Clim. Dynam., 39(7-8), 1781-1799, https://doi.org/10.1007/s00382-012-1308-1, 2012.

Hu, D., Tian, W., Xie, F. Shu, J., Dhomse, S.: Effects of meridional sea surface temperature changes on stratospheric temperature and circulation, Adv. Atmos. Sci., 31, 888-900. https://doi.org/10.1007/s00376-013-3152-6, 2014.

Hu, D., Guan, Z., Tian, W., \& Ren, R.: Recent strengthening of the stratospheric Arctic vortex response to warming in the central North Pacific, Nat. Commun., 9(1), 1697. https://doi.org/10.1038/s41467-018-04138-3, 2018.

Hu, D., Guo, Y., \& Guan, Z.: Recent weakening in the stratospheric planetary wave intensity in early winter, Geophys. Res. Lett., 46(7), 3953-3962, https://doi.org/10.1029/2019GL082113, 2019.

Huang, B., Peter W. Thorne, et. al.: Extended Reconstructed Sea Surface Temperature version 5 (ERSSTv5), Upgrades, validations, and intercomparisons, J. Climate, 30(20), 8179- 
571 Ialongo, I., Sofieva, V., Kalakoski, N., Tamminen, J., \& E. Kyrölä.: Ozone zonal asymmetry and

Kang, S. M. , Polvani, L. M. , Fyfe, J. C. , \& Sigmond, M.: Impact of polar ozone depletion on https://doi.org/10.1126/science.1202131, 2011. temperature as a possible indicator of spring total ozone, Atmos. Chem. Phys., 11(10), 28945-28967, https://doi.org/10.5194/acp-12-2865-2012, 2011. 

https://doi.org/10.2151/jmsj.2015-001, 2015.

594 Lin, P., Fu, Q., Solomon, S., \& Wallace, J. M.: Temperature trend patterns in southern hemisphere high latitudes: novel indicators of stratospheric change, J. Climate, 22(23), 6325-6341. https://doi.org/10.1175/2009JCLI2971.1, 2009. polar vortex, Sci. China. Ser. D., 52(3), 323-332, https://doi.org/10.1007/s11430-0090029-8, 2009.

600

601

602

Lin, P., Fu, Q., \& Hartmann, D.: Impact of tropical sst on stratospheric planetary waves in the southern hemisphere, J. Climate, 25(14), 5030-5046. https://doi.org/10.1175/JCLI-D-1100378.1, 2012.

Li, Y., \& Tian, W.: Different impact of central pacific and eastern pacific el nino on the duration of sudden stratospheric warming, Adv. Atmos. Sci., 34(06), 771-782. https://doi.org/10.1007/s00376-017-6286-0, 2017.

Li, Y., Tian, W., Xie, F., Wen, Z., Zhang, J., Hu, D., \& Han, Y.: The connection between the second leading mode of the winter North Pacific sea surface temperature anomalies and stratospheric sudden warming events, Clim. Dynam., 51(1-2), 581 - 595 . https://doi.org/10.1007/s00382-017-3942-0, 2018.

Lim, E. P., Hendon, H. H., Boschat, G. Hudson, D., Thompson, D. J., Dowdy, A., J., Arblaster, J. M.: Australian hot and dry extremes induced by weakenings of the stratospheric polar vortex, Nat. Geosci., 12, 896-901, https://doi.org/10.1038/s41561-019-0456-x, 2019.

Marsh, D. R., Mills, M. J., Kinnison, D. E., Lamarque, J. F., Calvo, N., \& Polvani, L. M.: Climate 
616 Nishii, K. and Nakamura, H.: Tropospheric influence on the diminished Antarctic ozone hole in September 2002, Geophys. Res. Lett., 31(16), L16103, https://doi.org/10.1029/2004GL019532, 2004.

619 620 Atmos. Sci., 62(3), 614-628. https://doi.org/10.1175/JAS-3323.1, 2005.

Neale, R. B., Richter, J., Park, S., Lauritzen, Lauritzen, P. H., Vavrus, S. J., Rasch, P. J., \& Zhang, M.:The mean climate of the community atmosphere model (cam4) in forced sst and fully coupled experiments, J. Climate, 26(14), 5150-5168, https://doi.org/10.1175/JCLI-D-12$00236.1,2013$.

Polvani, L. M., \& Bellomo, K.: The key role of ozone depleting substances in weakening the walker circulation in the second half of the 20th century, J. Climate, 32(5), 1411-1418. https://doi.org/10.1175/JCLI-D-17-0906.1, 2013.

Polvani, L. M., Wang, L., Aquila, V., \& Waugh, D. W.: The impact of ozone depleting substances on tropical upwelling, as revealed by the absence of lower stratospheric cooling since the late 1990s, J. Climate, 30(7), 2523-2534. https://doi.org/10.1175/JCLI-D-16-0532.1, 2017.

Polvani, L. M., Abalos, M., Garcia, R., Kinnison, D., \& Randel, W. J.: Significant weakening of Brewer-Dobson circulation trends over the 21 st century as a consequence of the Montreal Protocol, Geophys. Res. Lett., 45(1), 401-409, https://doi.org/10.1002/2017GL075345, 2018.

Randel, W. J., \& Wu, F.: Cooling of the arctic and antarctic polar stratospheres due to ozone 

275-316, https://doi.org/10.1029/1999RG900008, 1999.

Son, S. W., P. G. Edwin, K. H. Seo,: The impact of stratospheric ozone recovery on the Southern Hemisphere westerly jet, Science, 320(5882): 1486-1489, https://doi.org/10.1126/science.1155939, 2008.

643

Swart, N. C. \& Fyfe, J. C.: Observed and simulated changes in the Southern Hemisphere surface westerly wind-stress, Geophys. Res. Lett. 39(16), L16711, https://doi.org/10.1029/2012GL052810, 2012.

Solomon, S., Ivy, D. J., Kinnison, D., Mills, M. J., Neely, R. R., \& Schmidt, A.: Emergence of healing in the antarctic ozone layer, Science, 353(6296), 269-274, https://doi.org/10.1126/science.aae0061, 2016.

Son, S. W., Han, B. R., Garfinkel, C. I., Seo-Yeon, K., Rokjin, P., \& Luke, A. N., et al.: Tropospheric jet response to antarctic ozone depletion: an update with chemistry-climate model initiative (CCMI) models, Environ. $\quad$ Res. $\quad$ Lett., 13(5), 054024-. https://doi.org/10.1088/17489326/aabf21, 2018.

Susan, E., S., Douglass, A. R., Damon, M. R.: Why do antarctic ozone recovery trends vary?, J. Geophys. Res.-Atmos., 124(15), 8837-8850. https://doi.org/10.1029/2019JD030996, 2019. Shen, X., Wang, L., \& Osprey, S.: The southern hemisphere sudden stratospheric warming of september 2019, Sci. Bull., 65(21), 1800-1802. https://doi.org/10.1016/j.scib.2020.06.028, $2020 a$ 
658 Shen, X., Wang, L., \& Osprey, S.: Tropospheric forcing of the 2019 antarctic sudden stratospheric warming, Geophys.

Res. Lett., 47(20), e2020GLO89343, https://doi.org/10.1029/2020GL089343, 2020b.

Thompson, D., Solomon, S., Kushner, P. England, M., Grise, K. M., Karoly, D. J.: Signatures of the Antarctic ozone hole in Southern Hemisphere surface climate change, Nat. Geosci., 4, 741749. https://doi.org/10.1038/ngeo1296, 2011.

Trenberth, K. E., \& Fasullo, J. T.: An apparent hiatus in global warming?, Earth's Future, 1(1), 1932, https://doi.org/10.1002/2013EF000165, 2013.

Tian, W., Li, Y., Xie, F., Zhang, J., Chipperfield, M., \& Feng, W., Hu, Y., Zhao, S., Zhou, X., Zhang, Y. \& Ma, X.: The relationship between lower-stratospheric ozone at southern high latitudes and sea surface temperature in the east Asian marginal seas in austral spring, Atmos. Chem. Phys., 17(11), 6705-6722. https://doi.org/10.5194/acp-17-6705-2017, 2017.

Wang, T., Tian, W., Zhang, J., Xie, F., Zhang, R., Huang, J. \& Hu, D.: Connections between Spring Arctic Ozone and the Summer Circulation and Sea Surface Temperatures over the Western North Pacific, J. Climate, 33(7): 2907-2923, https://oi.org/10.1175/JCLI-D-19-0292.1, 2020.

WMO.: Scientific assessment of ozone depletion: 2010, World Meteorological Organization/United Nations Environment Programme Rep. 52, 516 pp, 2011.

WMO.: Antarctic ozone hole is smallest on record, World Meteorological Organization. Accessed October 2019 at https://public.wmo.int/en/media/news/antarctic-ozone-hole-smallestrecord, 2019.

Xia, Y., Xu, W., Hu, Y., \& Xie, F.: Southern-hemisphere high-latitude stratospheric warming 
682 Xie, F., Zhang, J., Huang, Z., Lu, J., \& Sun, C.: An estimate of the relative contributions of sea surface temperature variations in various regions to stratospheric change, J. Climate, 33(12), 4994-5011, https://doi.org/10.1175/JCLI-D-19-0743.1, 2020. 2019 Antarctic sudden stratospheric warming: Quasi-6-day wave burst and ionospheric effects, Geophys. Res. Lett., 47(1), e2019GL086577. https://doi.org/10.1029/2019GL086577, 2020. decreasing total column ozone over the tibetan plateau during winter and spring, Tellus B.,

Zhang, J., Tian, W. , Chipperfield, M. P. , Xie, F. , \& Huang, J.: Persistent shift of the arctic polar vortex towards the eurasian continent in recent decades, Nat. Clim. Change. 6, 1094-1099. https://doi.org/10.1038/nclimate3136, 2016. Kara Sea sea ice variability to the midlatitude circulation in a simplified model, Clim. Dynam. 50(17), 527-539. https://doi.org/10.1007/s00382-017-3624-y, 2018.

698 Zhang, J., Tian, W., Xie, F., Sang, W., Guo, D., Chipperfield, M., Feng, W., Hu, D.: Zonally asymmetric trends of winter total column ozone in the northern middle latitudes, Clim.

701 Zhang, R., Tian, W., Zhang, J., Huang, J., \& Xu, M.: The corresponding tropospheric environments 
706 Table 1. Configurations of experiments for SST trends.

\begin{tabular}{|c|c|}
\hline Experiments & Descriptions \\
\hline sstctrl & $\begin{array}{l}\text { Control run. Seasonal cycle of monthly mean global SST data } \\
\text { over } 1980-2000 \text { is derived from the ERSST v } 5 \text { dataset. Fixed } \\
\text { values of ozone greenhouse gases and aerosol fields in } 2000 \\
\text { are used. }\end{array}$ \\
\hline sstNH & $\begin{array}{l}\text { As in sstctrl, but with linear increments of SST in September } \\
\text { over } 2000-2017 \text { in } \mathrm{NH}\left(20^{\circ} \mathrm{N}-70^{\circ} \mathrm{N}\right) \text {. The applied global SST } \\
\text { anomalies are shown in Fig. } 7 \mathrm{a} \text {. }\end{array}$ \\
\hline sstSH & $\begin{array}{l}\text { As in sstctrl, but with linear increments of SST in September } \\
\text { over } 2000-2017 \text { in SH }\left(20^{\circ} \mathrm{S}-70^{\circ} \mathrm{S}\right) \text {. The applied global SST } \\
\text { anomalies are shown in Fig. } 7 \mathrm{~b} \text {. }\end{array}$ \\
\hline ssttrop & $\begin{array}{l}\text { As in sstctrl, but with linear increments of SST in September } \\
\text { over } 2000-2017 \text { in the tropics }\left(20^{\circ} \mathrm{S}-20^{\circ} \mathrm{N}\right) \text {. The applied global } \\
\text { SST anomalies are shown in Fig. } 7 \mathrm{c} \text {. }\end{array}$ \\
\hline sstSHtrop & $\begin{array}{l}\text { As in sstctrl, but with linear increments of SST in September } \\
\text { over } 2000-2017 \text { in SHtrop }\left(20^{\circ} \mathrm{N}-70^{\circ} \mathrm{S}\right) \text {. The applied global } \\
\text { SST anomalies are shown in Fig. } 7 \mathrm{~d} \text {. }\end{array}$ \\
\hline
\end{tabular}

707 Table 2. Configurations of experiments for the ozone recovery trend.

Experiments Descriptions




Control run. The seasonal cycle of monthly averaged global
SST data over 1980-2000 is derived from ERSST v5 dataset.
The seasonal cycle of monthly mean three-dimensional global
Ozone over 1980-2000 is derived from MERRA-2 dataset. The
GHGs and aerosol fields are specified to be fixed values in
2000.
As in O3ctrl, but superposed with linear increments of global
ozone in September over 2001-2017. The ozone data in 2002
are removed when the linear increments are calculated. The
applied ozone anomalies in Southern Hemisphere are shown
in Fig. S5.

Table 3. Correlations of stratospheric vertical wave flux time series (area-weighted from $100 \mathrm{hPa}$ to $30 \mathrm{hPa}$ over $70^{\circ} \mathrm{S}-50^{\circ} \mathrm{S}$ ) between different reanalysis dataset.

\begin{tabular}{ccccc}
\hline & ERA-Interim & JRA-55 & MERRA-2 & NCEP-2 \\
\hline ERA-Interim & $1.00(\mathrm{p}=0.00)$ & $0.99(\mathrm{p}<0.01)$ & $0.98(\mathrm{p}<0.01)$ & $0.93(\mathrm{p}<0.01)$ \\
\hline JRA-55 & & $1.00(\mathrm{p}=0.00)$ & $0.98(\mathrm{p}<0.01)$ & $0.93(\mathrm{p}<0.01)$ \\
\hline MERRA-2 & & $1.00(\mathrm{p}=0.00)$ & $0.94(\mathrm{p}<0.01)$ \\
\hline NCEP-2 & & & $1.00(\mathrm{p}=0.00)$ \\
\hline
\end{tabular}

710

711 Figure captions:

712 FIG. 1. Trends of southern hemisphere (a,d) stratospheric E-P flux (arrows, units of

713 horizontal and vertical components are $10^{5}$ and $10^{3} \mathrm{~kg} \cdot \mathrm{s}^{-2}$ per year, respectively) and its

714 divergence (shadings) with their (b, e) wave-1 components and (c, f) wave-2

715 components over (a, b, c) 1980-2000 and (d, e, f) 2000-2017 in September derived from

716 MERRA-2 dataset. The stippled regions indicate the trend of E-P flux divergence

717 significant at/above the $90 \%$ confidence level. The green contours from outside to

718 inside (corresponding to $\mathrm{p}=0.1,0.05$ ) indicate the trend of vertical E-P flux significant 
719 at the $90 \%$ and $95 \%$ confidence level, respectively.

720 FIG. 2. (a) The mean time series (solid line) and piecewise (during 1980-2000 and

721 2000-2018) linear regressions (dashed lines) of vertical E-P flux area-weighted from

$722100 \mathrm{hPa}$ to $30 \mathrm{hPa}$ over $70^{\circ} \mathrm{S}-50^{\circ} \mathrm{S}$ in September during 1980-2018 derived from ERA-

723 Interim (yellow), MERRA-2 (blue), JRA-55 (red) and NCEP-2 (green). Figure (b) is

724 the same as Figure (a), except for that the data in 2002 are removed. (c, d, e, f) The

725 trends (dots) and uncertainties (error bars) calculated during various periods using the

726 change-point method with different beginning and ending years (titles). Circles and

727 squares in Figures (c, d, e, f) represent positive trends from beginning years to change-

728 point years (x-axes) and negative trends from change-point years to ending years,

729 respectively. Different colors of dots and error bars in Figures (c, d, e, f) correspond to

730 colors in Figure (a), which represent trends and uncertainties derived from different

731 datasets. The long and short error bars in same color reflect the $95 \%$ and $90 \%$

732 confidence intervals calculated by two-tailed $t$ test. The error bar is omitted when the

733 significance of trend is lower than corresponding confidence level. Negative trends and

734 corresponding uncertainties with the beginning change-point years after 2005 are also

735 omitted, since the trend value shows large fluctuation with shortening of time series.

736 Figures $(g, h, i, j)$ are the same as Figures (c, d, e, f), except that the data in 2002 are

737 removed when calculating trends and uncertainties.

738 FIG. 3. Trends (shadings) and climatological distributions (contours with an interval

739 of 20 gpm, positive and negative values are depicted by solid and dashed lines

740 respectively, zeroes are depicted by thick solid lines) of southern hemispheric (a) 500 
$741 \mathrm{hPa}$ geopotential height zonal deviations with their (b) wave-1 component and (c)

742 wave-2 component in September during 2000-2017 derived from MERRA-2 dataset.

743 Trends of southern hemispheric (d) tropospheric E-P flux (arrows, units of horizontal

744 and vertical components are $3 \times 10^{5}$ and $3 \times 10^{3} \mathrm{~kg} \cdot \mathrm{s}^{-2}$ per year, respectively) and its

745 vertical component (shading) with their (e) wave-1 component and (f) wave-2

746 component in September during 2000-2017 derived from MERRA-2 dataset. The

747 stippled regions represent the trend significant at/above the $90 \%$ confidence level.

748 FIG. 4. Trends of SST in September over (a) 1980-2000 and (b) 2000-2017 derived

749 from ERSST v5 dataset. The stippled regions represent the trends significant at/above

750 the $90 \%$ confidence level.

751 FIG. 5. Trend significance of the first three SST principal components (PCs) in (a) the

752 extratropical southern hemisphere $\left(\mathrm{SH}, 70^{\circ} \mathrm{S}-20^{\circ} \mathrm{S}\right),(\mathrm{b})$ the tropics (TROP, $\left.20^{\circ} \mathrm{S}-20^{\circ} \mathrm{N}\right)$,

753 (c) the extratropical northern hemisphere $\left(\mathrm{NH}, 20^{\circ} \mathrm{N}-70^{\circ} \mathrm{N}\right)$, (d) the extratropical

754 southern hemisphere and the tropics (SHtrop, $\left.70^{\circ} \mathrm{S}-20^{\circ} \mathrm{N}\right),(\mathrm{e})$ the extratropical northern

755 hemisphere and the tropics (NHtrop, $\left.20^{\circ} \mathrm{S}-70^{\circ} \mathrm{N}\right)$, (f) the globe $\left(70^{\circ} \mathrm{S}-70^{\circ} \mathrm{N}\right)$ and the

756 corresponding $(\mathrm{g}, \mathrm{h}, \mathrm{i}, \mathrm{j}, \mathrm{k}, \mathrm{l})$ correlation significances between them and vertical E-P

757 flux (Fz, area-weighted from $100 \mathrm{hPa}$ to $30 \mathrm{hPa}$ over $\left.70^{\circ} \mathrm{S}-50^{\circ} \mathrm{S}\right)$ during different

758 beginning years (x-axes) and ending years (y-axes). The red and blue dots indicate

759 positive and negative trend or correlation coefficient are significant, respectively. The

760 black dots indicate the trends or correlation coefficients are not significant. The stars

761 indicate that the trends and the corresponding correlation coefficients are both significant. Each panel is divided into three regions from bottom to top, corresponding 
763 to the first, the second and the third principal components, respectively. The criterion

764 to distinguish whether the trends and correlations are significant or not is the $90 \%$

765 confidence level.

766 FIG. 6. (a, b, c) The first three EOF patterns of SST in SHtrop region. (d, e, f) The original time series of the first three principle components (PCs, blue solid lines correspond to left inverted y-axes) and stratospheric vertical E-P flux (Fz, areaweighted from $100 \mathrm{hPa}$ to $30 \mathrm{hPa}$ over $70^{\circ} \mathrm{S}-50^{\circ} \mathrm{S}$, red solid lines correspond to right yaxes) in September during 2000-2017. The blue and red dashed lines in (d, e, f) represent the linear regressions of PC time series and Fz time series, respectively. The meaning of (g, h, i) are the same as (d, e, f) correspondingly, except the detrended time series. The unbracketed and bracketed numbers in $(\mathrm{g}, \mathrm{h}, \mathrm{i})$ represent the correlation coefficients between detrended PC time series and Fz time series and the corresponding $\mathrm{p}$ values calculated by two-tailed $\mathrm{t}$ test, respectively.

FIG. 7. Differences in SST forcing field between sensitive experiments ((a) sstNH; (b) sstSH; (c) ssttrop; (d) sstSHtrop) and the control experiment (sstctrl).

778 FIG. 8. Differences (shadings) of (a, d, g, j) $500 \mathrm{hPa}$ geopotential height zonal 779 deviations with their (b, e, h, k) wave- 1 component and (c, f, i, l) wave- 2 component 780 between sensitive experiments ((a, b, c) sstNH; (d, e, f) sstSH; (g, h, i) ssttrop; (j, k, l) 781 sstSHtrop) and the control experiment (sstctrl). The mean distributions (contours with 782 an interval of $20 \mathrm{gpm}$, positive and negative values are depicted by solid and dashed 783 lines respectively, zeroes are depicted by thick solid lines) of them are derived from the control experiment. The stippled regions represent the mean difference significant 
785 at/above the $90 \%$ confidence level.

786 FIG. 9. Differences of (a, d, g, j) stratospheric E-P flux (arrows, units in horizontal and

787 vertical components are $0.05 \times 10^{7}$ and $0.05 \times 10^{5} \mathrm{~kg} \cdot \mathrm{s}^{-2}$, respectively) and its divergence

788 (shadings) with their (b, e, h, k) wave-1 component and (c, f, i, l) wave-2 component between sensitive experiments ((a, b, c) sstNH; (d, e, f) sstSH; (g, h, i) ssttrop; (j, k, l) sstSHtrop) and the control experiment (sstctrl). The stippled regions represent the mean differences of E-P flux divergence significant at/above the $90 \%$ confidence level. The

792 green contours from outside to inside (corresponding to $\mathrm{p}=0.1,0.05$ ) represent the mean differences of vertical E-P flux significant at the $90 \%$ and $95 \%$ confidence levels, respectively.

795 FIG. 10. (a, b, c, d) Frequency distributions (pillars, blue for control experiment and 796 orange for sensitive experiments) of vertical E-P flux (Fz, area-weighted from $200 \mathrm{hPa}$ 797 to $10 \mathrm{hPa}$ over $70^{\circ} \mathrm{S}-50^{\circ} \mathrm{S}$ ) and its 5-point low-pass filtered fitting curves (solid lines, blue for control experiment and red for sensitive experiments) derived from 100 ensemble members of the control experiment (sstctrl) and sensitive experiments ((a) sstNH; (b) sstSH; (c) ssttrop; (d) sstSHtrop), respectively. (e) Mean differences (grey pillars) and corresponding uncertainties (error bars) of $\mathrm{Fz}$ between sensitive experiments and the control experiment. The blue and red error bars reflect the $90 \%$ and $95 \%$ confidence levels calculated by two-tailed t test, respectively. The error bar is

804 omitted when the significance of mean difference is lower than the corresponding 805 confidence level.

806 FIG. 11. Differences of (a) stratospheric E-P flux (arrows, units in horizontal and 
807 vertical components are $0.02 \times 10^{7}$ and $0.05 \times 10^{5} \mathrm{~kg} \cdot \mathrm{s}^{-2}$, respectively) and its divergence

808 (shadings) with their (b) wave-1 component and (c) wave-2 component between the

809 sensitive experiment (O3sen) and the control experiment (O3ctrl). The stippled regions represent the mean differences of E-P flux divergence significant at/above the $90 \%$

811 confidence level. The green contours from outside to inside (corresponding to $\mathrm{p}=0.1$,

8120.05 ) represent the mean differences of vertical E-P flux significant at the $90 \%$ and $95 \%$

813 confidence levels, respectively. (d) Frequency distributions (pillars, blue for O3ctrl and

814 orange for O3sen) of vertical E-P flux (Fz, area-weighted from $200 \mathrm{hPa}$ to $10 \mathrm{hPa}$ over

$81570^{\circ} \mathrm{S}-50^{\circ} \mathrm{S}$ ) and it 5-point low-pass filtered fitting curves (solid lines, blue for O3ctrl

816 and red for O3sen) derived from 100 ensemble members.

817 FIG. 12. (a) Trends of southern hemispheric Brewer-Dobson circulation (arrows, units

818 in horizontal and vertical components are $0.2 \times 10^{-2}$ and $0.2 \times 10^{-4} \mathrm{~m} \cdot \mathrm{s}^{-1}$ per year,

819 respectively) and its stream function (shadings) in September during (a) 1980-2000 and

820 (b) 2000-2017 derived from MERRA-2 dataset. Data in 2002 are removed when trends

821 are calculated in Figure (b). (c) Differences of Brewer-Dobson circulation (arrows,

822 units in horizontal and vertical components are $10^{-2}$ and $10^{-4} \mathrm{~m} \cdot \mathrm{s}^{-1}$, respectively) and its

823 stream function (shadings) between the O3ctrl and O3sen. (d, e, f) Differences of

824 Brewer-Dobson circulation and its stream function between the control experiment

825 (sstctrl) and various sensitive experiments ((d) sstSH; (e) ssttrop; (f) sstSHtrop) with

826 SST changes. The stippled regions represent the trends or differences of the stream

827 function significant at/above the $90 \%$ confidence level. The green contours from outside to inside (corresponding to $\mathrm{p}=0.1,0.05$ ) represent the trends or differences of 
829 the vertical components significant at the $90 \%$ and $95 \%$ confidence levels, respectively.

830
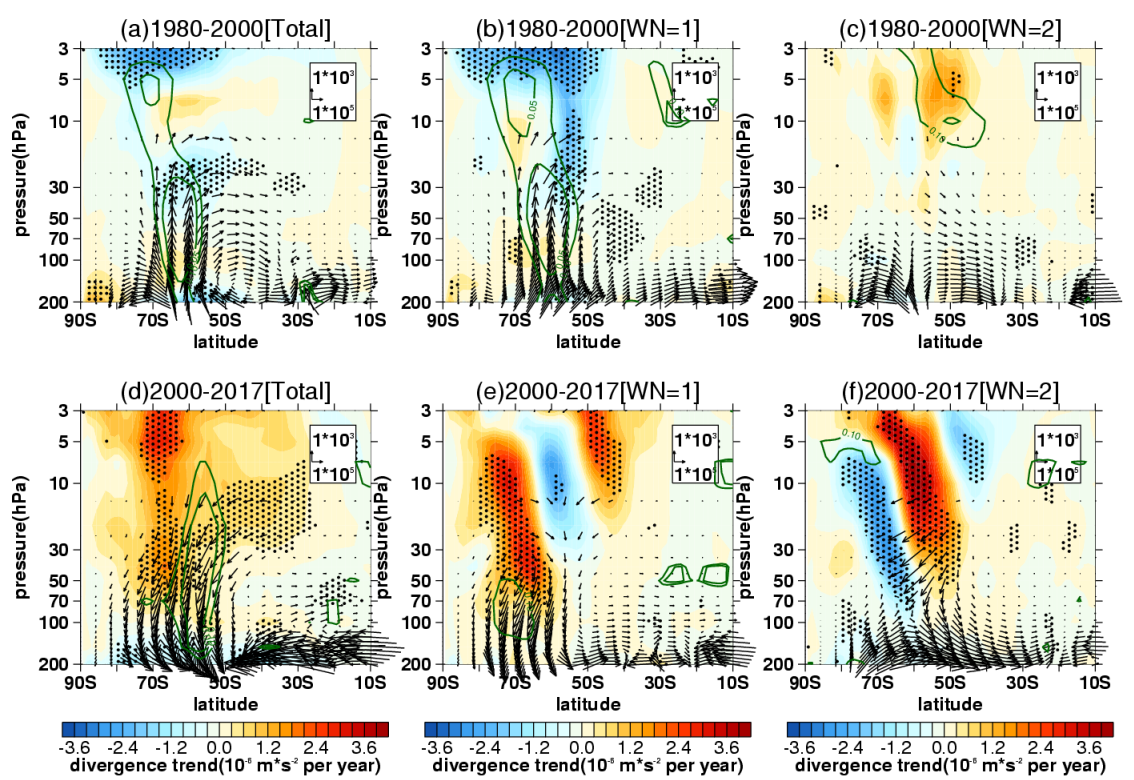

832 FIG. 1. Trends of southern hemisphere (a, d) stratospheric E-P flux (arrows, units of

833 horizontal and vertical components are $10^{5}$ and $10^{3} \mathrm{~kg} \cdot \mathrm{s}^{-2}$ per year, respectively) and its

834 divergence (shadings) with their (b, e) wave-1 components and (c, f) wave-2

835 components over (a, b, c) 1980-2000 and (d, e, f) 2000-2017 in September derived from

836 MERRA-2 dataset. The stippled regions indicate the trend of E-P flux divergence

837 significant at/above the $90 \%$ confidence level. The green contours from outside to

838 inside (corresponding to $\mathrm{p}=0.1,0.05$ ) indicate the trend of vertical E-P flux significant

839 at the $90 \%$ and $95 \%$ confidence level, respectively. 

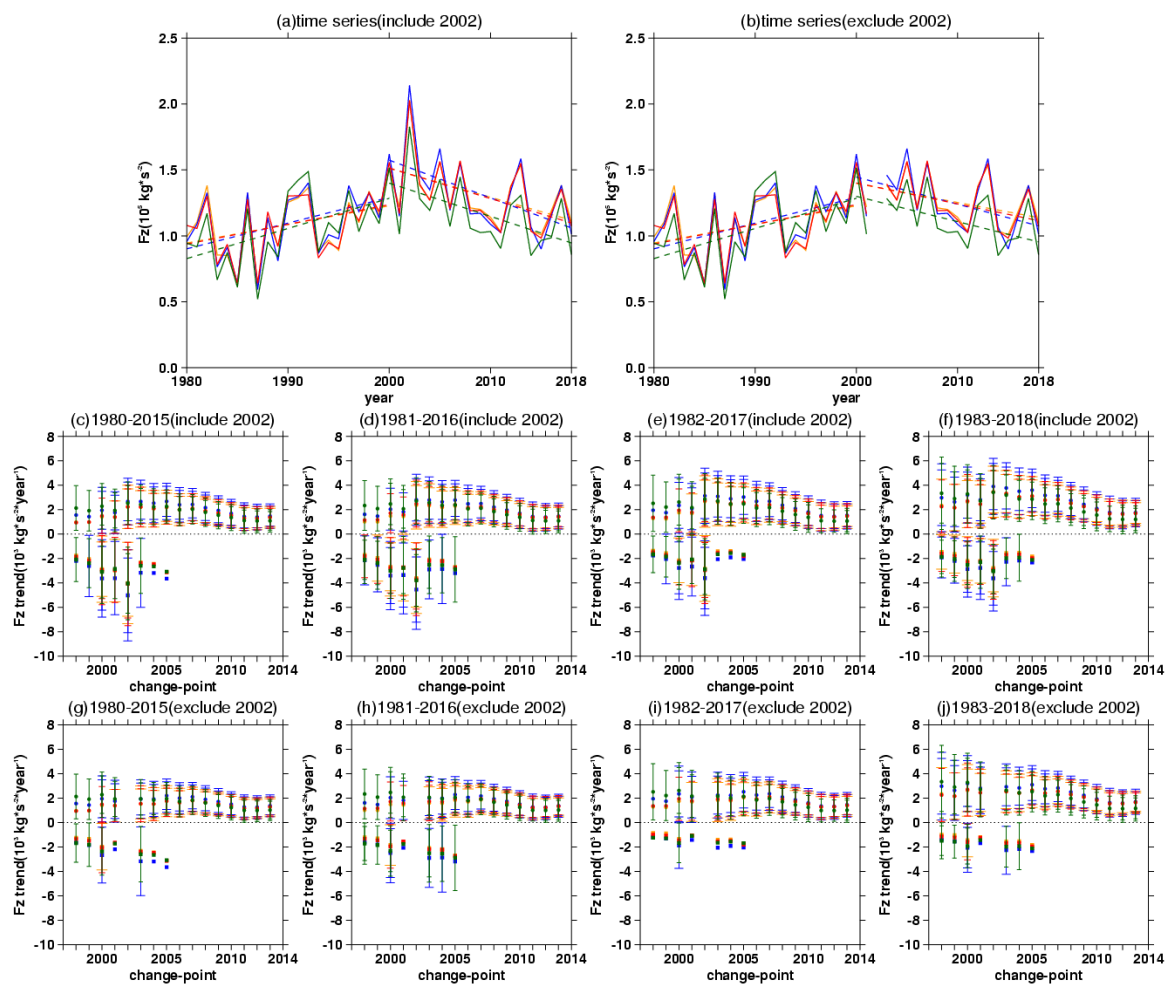

841 FIG. 2. (a) The mean time series (solid line) and piecewise (during 1980-2000 and 2000-2018) linear regressions (dashed lines) of vertical E-P flux area-weighted from $100 \mathrm{hPa}$ to $30 \mathrm{hPa}$ over $70^{\circ} \mathrm{S}-50^{\circ} \mathrm{S}$ in September during 1980-2018 derived from ERAInterim (yellow), MERRA-2 (blue), JRA-55 (red) and NCEP-2 (green). Figure (b) is the same as Figure (a), except for that the data in 2002 are removed. (c, d, e, f) The trends (dots) and uncertainties (error bars) calculated during various periods using the change-point method with different beginning and ending years (titles). Circles and squares in Figures $(c, d, e, f)$ represent positive trends from beginning years to change-

849 point years (x-axes) and negative trends from change-point years to ending years, respectively. Different colors of dots and error bars in Figures (c, d, e, f) correspond to colors in Figure (a), which represent trends and uncertainties derived from different 
852 datasets. The long and short error bars in same color reflect the $95 \%$ and $90 \%$

853 confidence intervals calculated by two-tailed $t$ test. The error bar is omitted when the

854 significance of trend is lower than corresponding confidence level. Negative trends and corresponding uncertainties with the beginning change-point years after 2005 are also omitted, since the trend value shows large fluctuation with shortening of time series.

857 Figures $(g, h, i, j)$ are the same as Figures (c, d, e, f), except that the data in 2002 are removed when calculating trends and uncertainties.
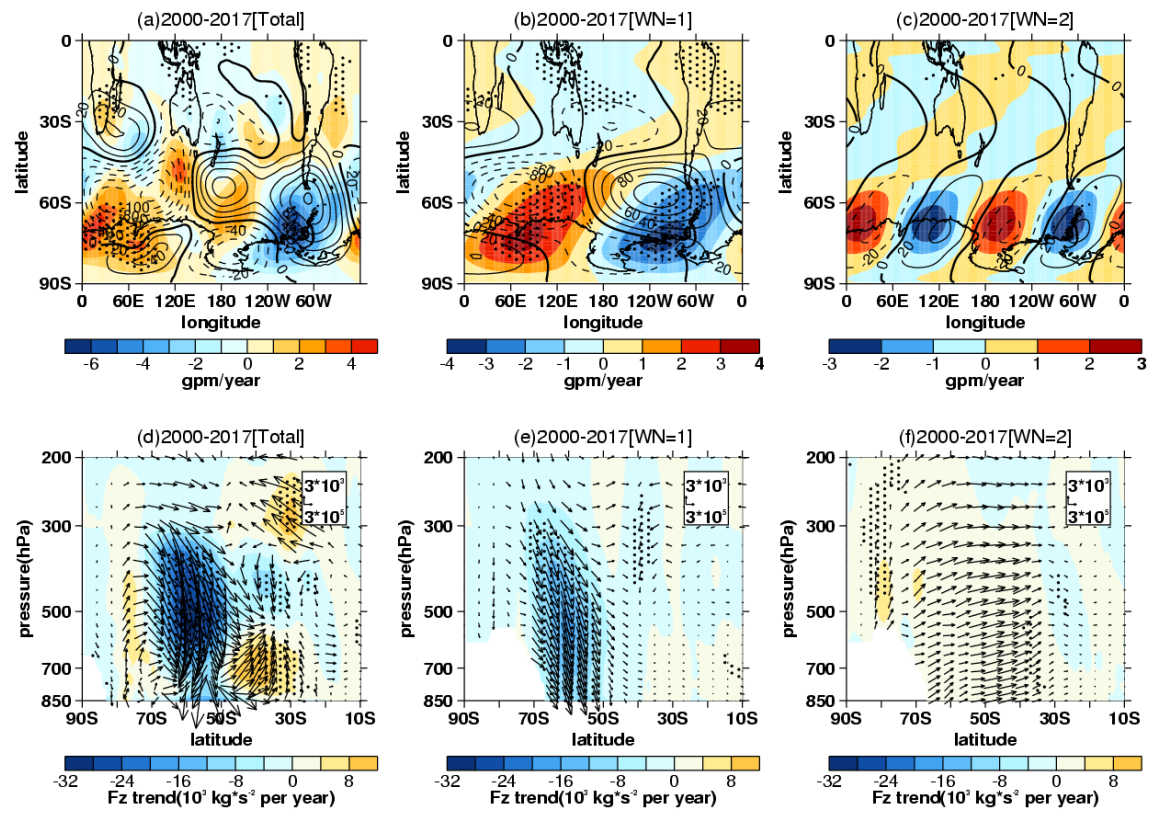

860 FIG. 3. Trends (shadings) and climatological distributions (contours with an interval

861 of 20 gpm, positive and negative values are depicted by solid and dashed lines

862 respectively, zeroes are depicted by thick solid lines) of southern hemispheric (a) 500

$863 \mathrm{hPa}$ geopotential height zonal deviations with their (b) wave-1 component and (c) wave-2 component in September during 2000-2017 derived from MERRA-2 dataset. 
866 and vertical components are $3 \times 10^{5}$ and $3 \times 10^{3} \mathrm{~kg} \cdot \mathrm{s}^{-2}$ per year, respectively) and its

867 vertical component (shading) with their (e) wave-1 component and (f) wave-2

868 component in September during 2000-2017 derived from MERRA-2 dataset. The

869 stippled regions represent the trend significant at/above the $90 \%$ confidence level.
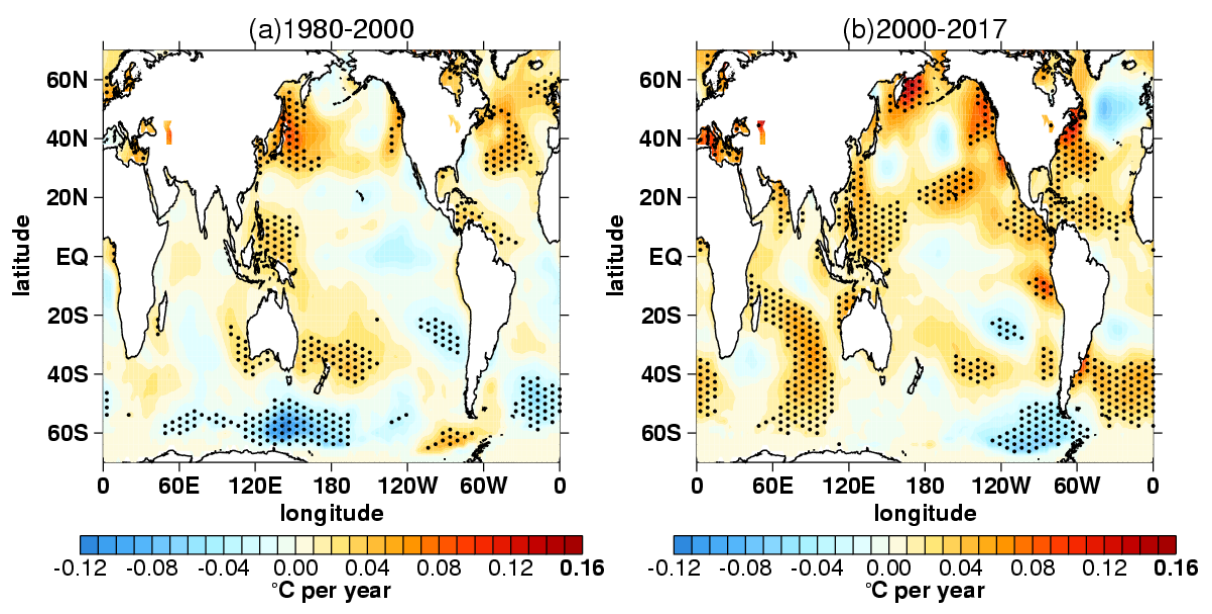

871 FIG. 4. Trends of SST in September over (a) 1980-2000 and (b) 2000-2017 derived

872 from ERSST v5 dataset. The stippled regions represent the trends significant at/above

873 the $90 \%$ confidence level. 
(a)trend $\mathrm{SH}$

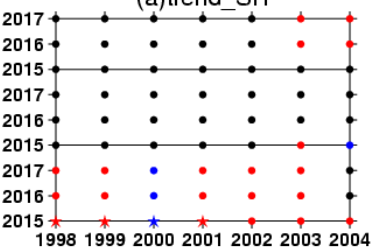
(d)trend_SHtrop

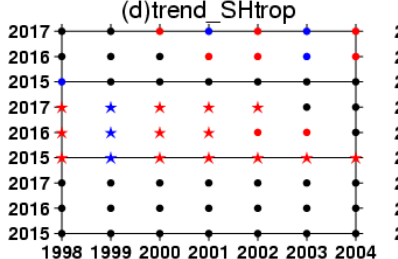
(g)cor_SH
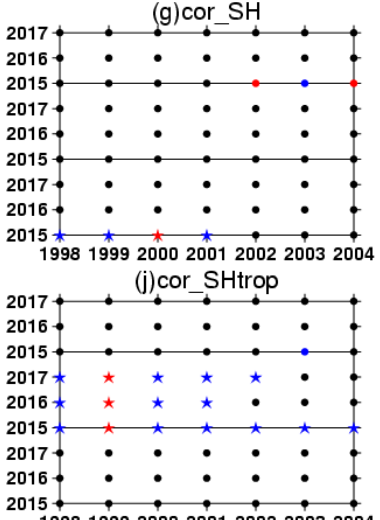

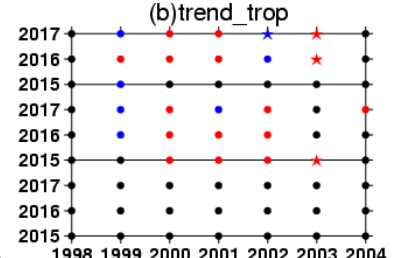

(e)trend NHtrop

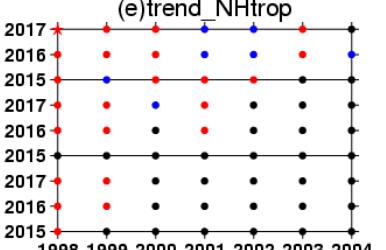

(h)cor_trop

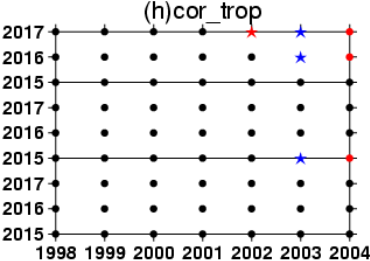

199819992000200120022003200

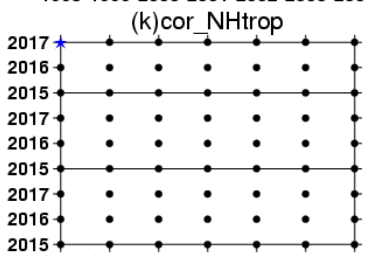

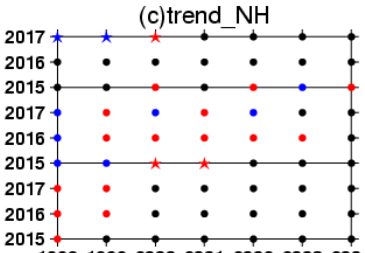

20032004

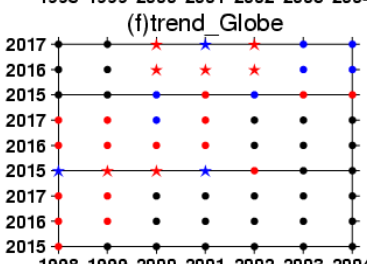

2001200220032004
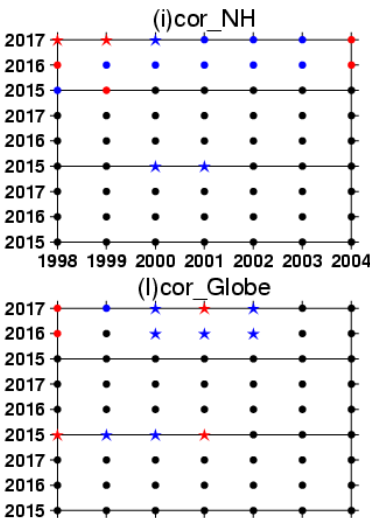

875 FIG. 5. Trend significance of the first three SST principal components (PCs) in (a) the

876 extratropical southern hemisphere ( $\left.\mathrm{SH}, 70^{\circ} \mathrm{S}-20^{\circ} \mathrm{S}\right)$, (b) the tropics (TROP, $20^{\circ} \mathrm{S}-20^{\circ} \mathrm{N}$ ),

877 (c) the extratropical northern hemisphere $\left(\mathrm{NH}, 20^{\circ} \mathrm{N}-70^{\circ} \mathrm{N}\right)$, (d) the extratropical

878 southern hemisphere and the tropics (SHtrop, $\left.70^{\circ} \mathrm{S}-20^{\circ} \mathrm{N}\right)$, (e) the extratropical northern

879 hemisphere and the tropics (NHtrop, $20^{\circ} \mathrm{S}-70^{\circ} \mathrm{N}$ ), (f) the globe $\left(70^{\circ} \mathrm{S}-70^{\circ} \mathrm{N}\right.$ ) and the

880 corresponding $(\mathrm{g}, \mathrm{h}, \mathrm{i}, \mathrm{j}, \mathrm{k}, \mathrm{l})$ correlation significances between them and vertical E-P

881 flux $\left(\mathrm{Fz}\right.$, area-weighted from $100 \mathrm{hPa}$ to $30 \mathrm{hPa}$ over $\left.70^{\circ} \mathrm{S}-50^{\circ} \mathrm{S}\right)$ during different

882 beginning years (x-axes) and ending years (y-axes). The red and blue dots indicate

883 positive and negative trend or correlation coefficient are significant, respectively. The

black dots indicate the trends or correlation coefficients are not significant. The stars 
885 indicate that the trends and the corresponding correlation coefficients are both

886 significant. Each panel is divided into three regions from bottom to top, corresponding

887 to the first, the second and the third principal components, respectively. The criterion

888 to distinguish whether the trends and correlations are significant or not is the $90 \%$

889 confidence level.
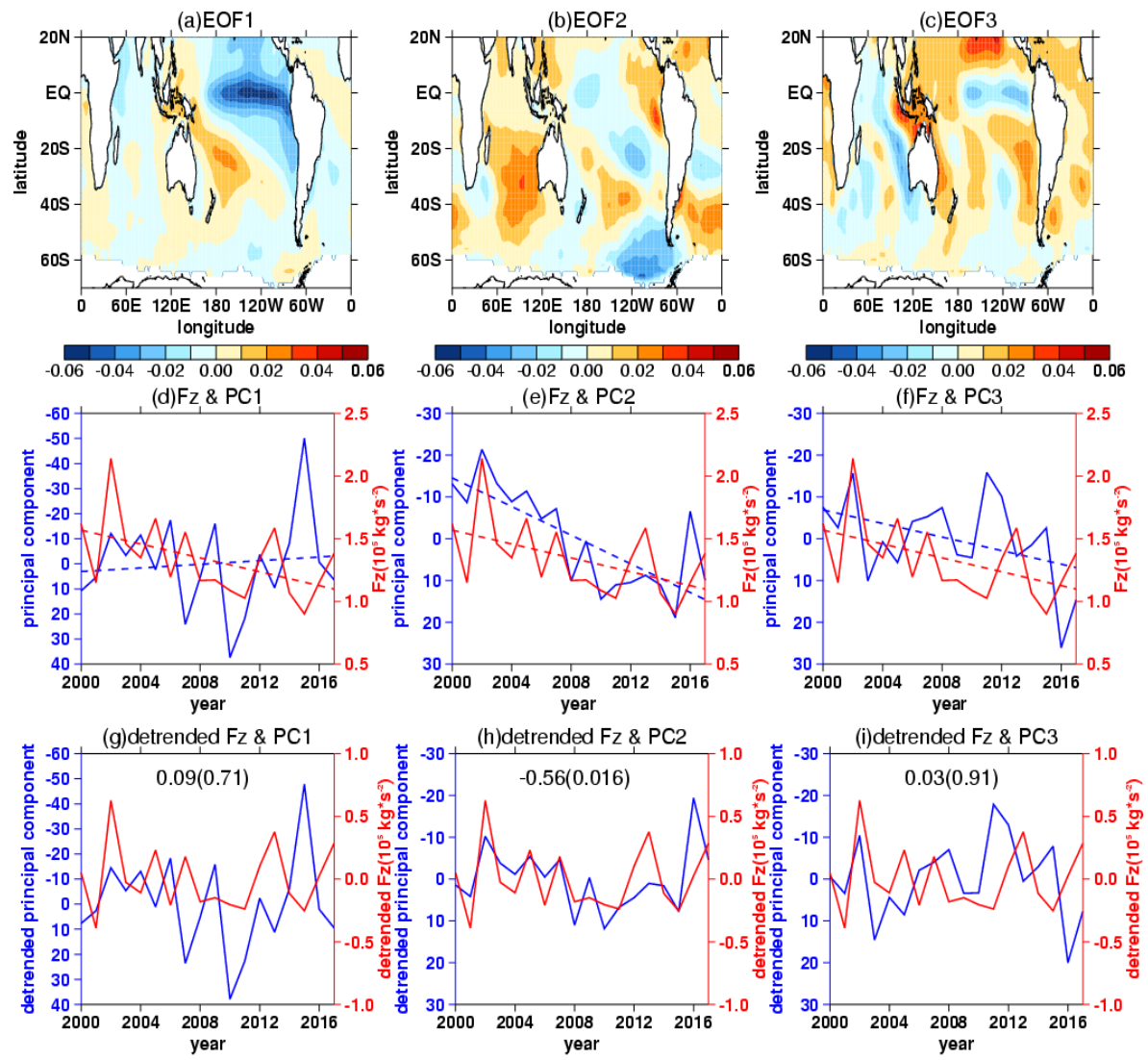

890 year

year

891 FIG. 6. (a, b, c) The first three EOF patterns of SST in SHtrop region. (d, e, f) The

892 original time series of the first three principle components (PCs, blue solid lines

893 correspond to left inverted y-axes) and stratospheric vertical E-P flux (Fz, area-

894 weighted from $100 \mathrm{hPa}$ to $30 \mathrm{hPa}$ over $70^{\circ} \mathrm{S}-50^{\circ} \mathrm{S}$, red solid lines correspond to right y- 
896 represent the linear regressions of PC time series and Fz time series, respectively. The

897 meaning of $(\mathrm{g}, \mathrm{h}, \mathrm{i})$ are the same as $(\mathrm{d}, \mathrm{e}, \mathrm{f})$ correspondingly, except the detrended time

898 series. The unbracketed and bracketed numbers in $(\mathrm{g}, \mathrm{h}, \mathrm{i})$ represent the correlation coefficients between detrended PC time series and Fz time series and the corresponding $\mathrm{p}$ values calculated by two-tailed $\mathrm{t}$ test, respectively.
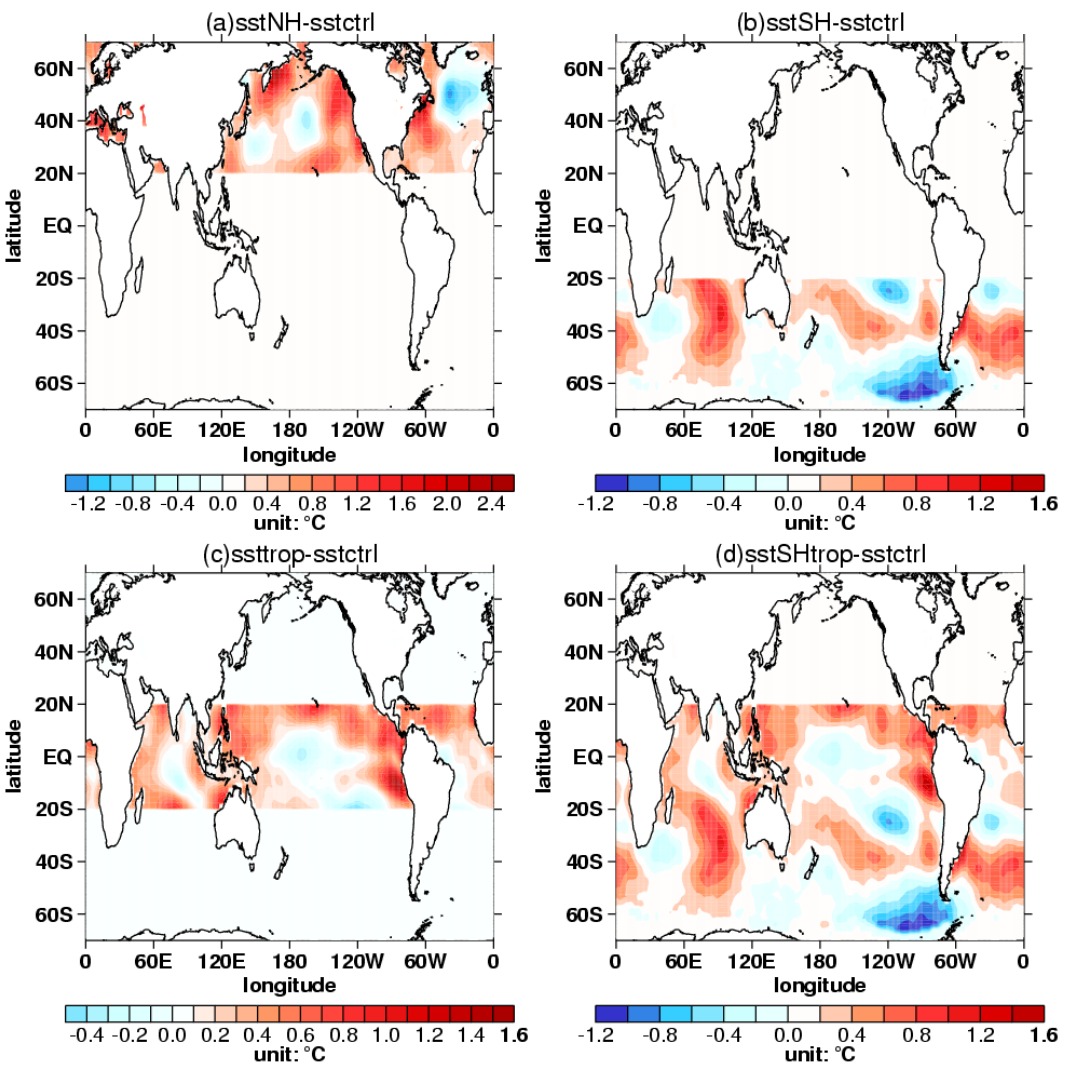

FIG. 7. Differences in SST forcing field between sensitive experiments ((a) sstNH; (b)

903 sstSH; (c) ssttrop; (d) sstSHtrop) and the control experiment (sstctrl). 

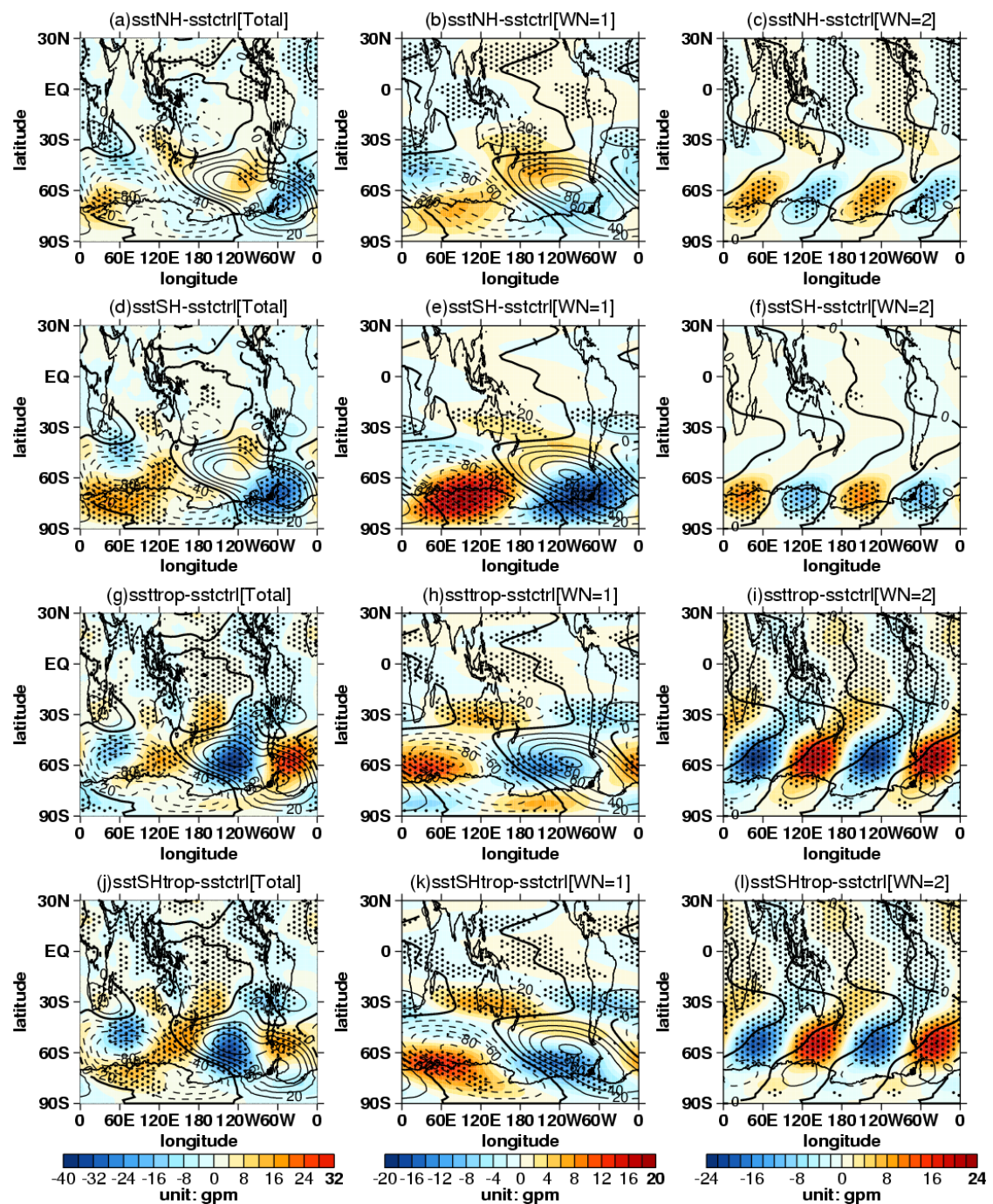

FIG. 8. Differences (shadings) of (a, d, g, j) $500 \mathrm{hPa}$ geopotential height zonal

906 deviations with their (b, e, h, k) wave-1 component and (c, f, i, l) wave-2 component

907 between sensitive experiments ((a, b, c) sstNH; (d, e, f) sstSH; (g, h, i) ssttrop; (j, k, l)

908 sstSHtrop) and the control experiment (sstctrl). The mean distributions (contours with

909 an interval of 20 gpm, positive and negative values are depicted by solid and dashed

910 lines respectively, zeroes are depicted by thick solid lines) of them are derived from the 
911 control experiment. The stippled regions represent the mean difference significant

912 at/above the $90 \%$ confidence level.
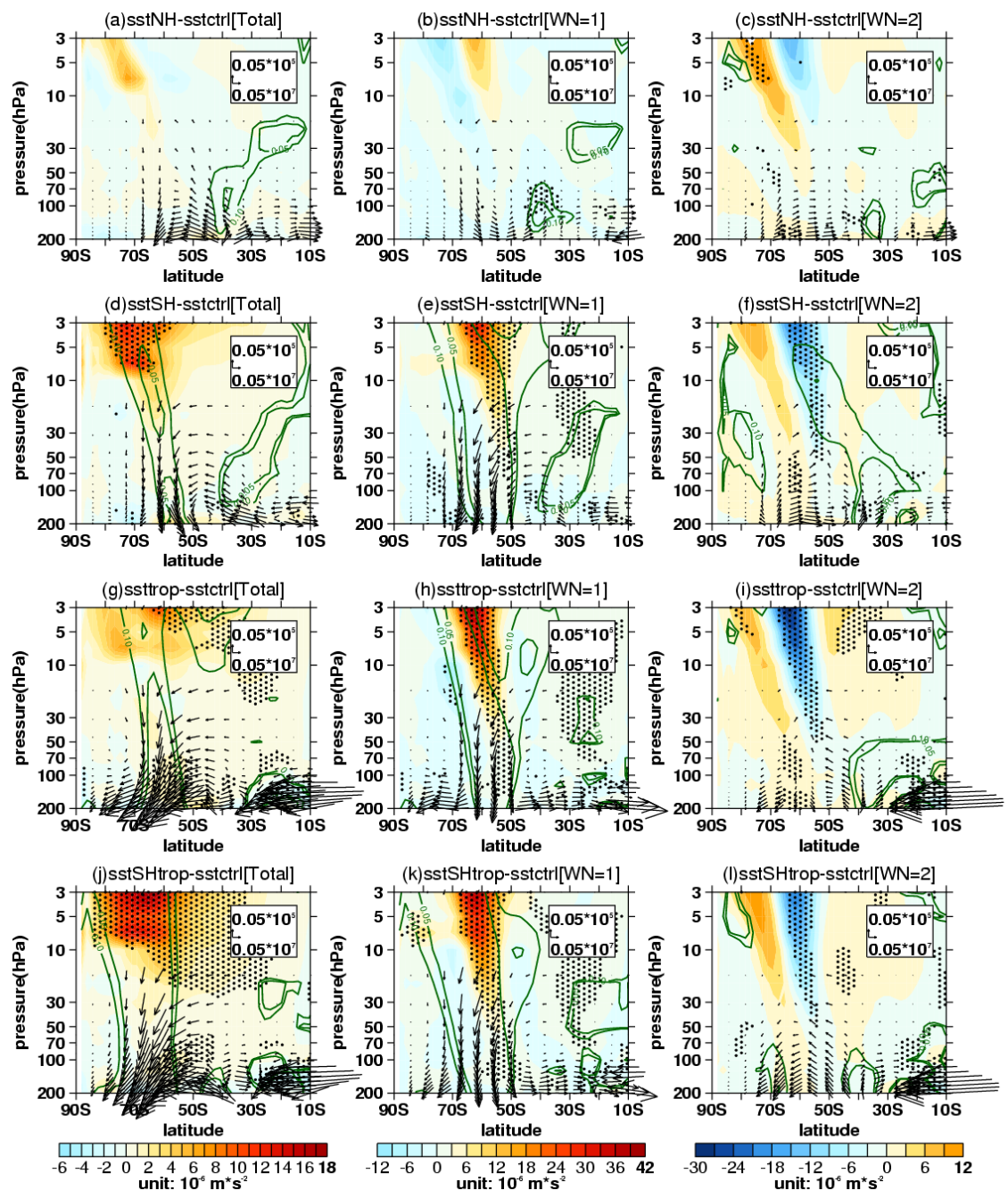

914 FIG. 9. Differences of ( $a, d, g, j)$ stratospheric E-P flux (arrows, units in horizontal and

915 vertical components are $0.05 \times 10^{7}$ and $0.05 \times 10^{5} \mathrm{~kg} \cdot \mathrm{s}^{-2}$, respectively) and its divergence

916 (shadings) with their (b, e, h, k) wave-1 component and (c, f, i, l) wave-2 component

917 between sensitive experiments ((a, b, c) sstNH; (d, e, f) sstSH; (g, h, i) ssttrop; (j, k, l) 
919 differences of E-P flux divergence significant at/above the $90 \%$ confidence level. The

920 green contours from outside to inside (corresponding to $\mathrm{p}=0.1,0.05$ ) represent the mean

921 differences of vertical E-P flux significant at the $90 \%$ and $95 \%$ confidence levels,

922 respectively.
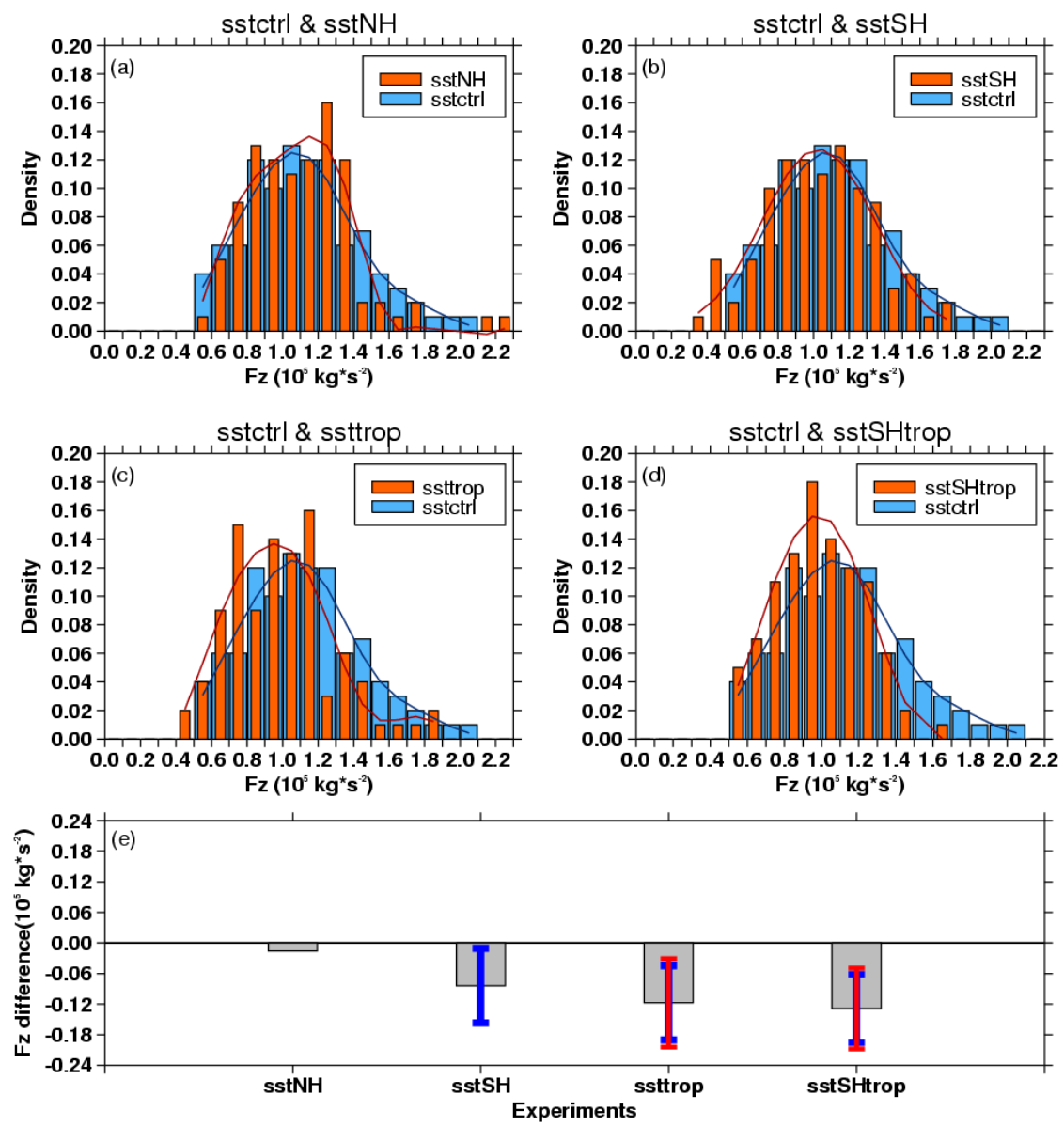

924 FIG. 10. (a, b, c, d) Frequency distributions (pillars, blue for control experiment and

925 orange for sensitive experiments) of vertical E-P flux (Fz, area-weighted from $200 \mathrm{hPa}$

926 to $10 \mathrm{hPa}$ over $70^{\circ} \mathrm{S}-50^{\circ} \mathrm{S}$ ) and its 5-point low-pass filtered fitting curves (solid lines,

927 blue for control experiment and red for sensitive experiments) derived from 100 
929 sstNH; (b) sstSH; (c) ssttrop; (d) sstSHtrop), respectively. (e) Mean differences (grey

930 pillars) and corresponding uncertainties (error bars) of $\mathrm{Fz}$ between sensitive

931 experiments and the control experiment. The blue and red error bars reflect the $90 \%$ confidence level.
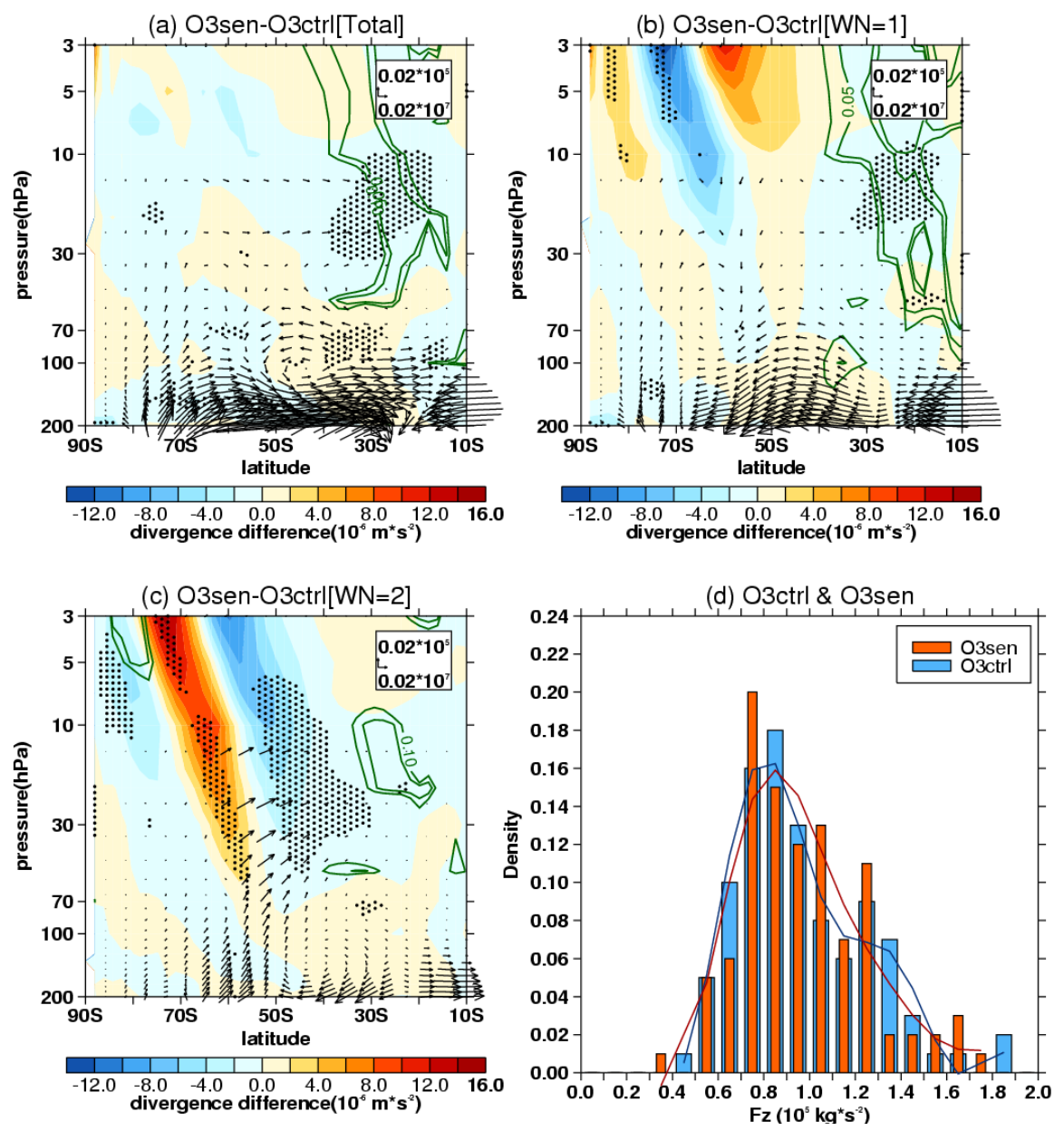

936 FIG. 11. Differences of (a) stratospheric E-P flux (arrows, units in horizontal and 
937 vertical components are $0.02 \times 10^{7}$ and $0.05 \times 10^{5} \mathrm{~kg} \cdot \mathrm{s}^{-2}$, respectively) and its divergence

938 (shadings) with their (b) wave-1 component and (c) wave-2 component between the

939 sensitive experiment (O3sen) and the control experiment (O3ctrl). The stippled regions

940 represent the mean differences of E-P flux divergence significant at/above the $90 \%$

941 confidence level. The green contours from outside to inside (corresponding to $\mathrm{p}=0.1$, and red for O3sen) derived from 100 ensemble members.
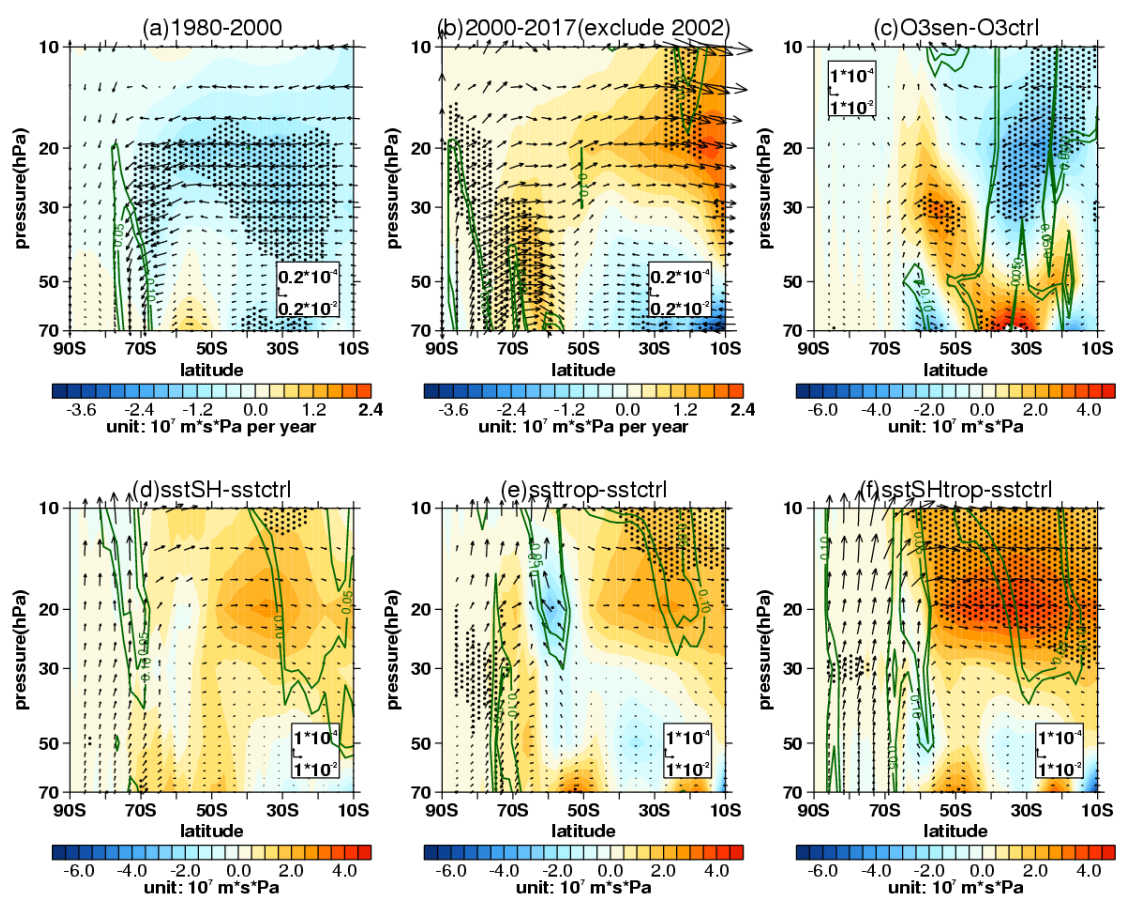

FIG. 12. (a) Trends of southern hemispheric Brewer-Dobson circulation (arrows, units

949 in horizontal and vertical components are $0.2 \times 10^{-2}$ and $0.2 \times 10^{-4} \mathrm{~m} \cdot \mathrm{s}^{-1}$ per year, 
950 respectively) and its stream function (shadings) in September during (a) 1980-2000 and

951 (b) 2000-2017 derived from MERRA-2 dataset. Data in 2002 are removed when trends

952 are calculated in Figure (b). (c) Differences of Brewer-Dobson circulation (arrows,

953 units in horizontal and vertical components are $10^{-2}$ and $10^{-4} \mathrm{~m} \cdot \mathrm{s}^{-1}$, respectively) and its

954 stream function (shadings) between the O3ctrl and O3sen. (d, e, f) Differences of

955 Brewer-Dobson circulation and its stream function between the control experiment

956 (sstctrl) and various sensitive experiments ((d) sstSH; (e) ssttrop; (f) sstSHtrop) with

957 SST changes. The stippled regions represent the trends or differences of the stream

958 function significant at/above the $90 \%$ confidence level. The green contours from

959 outside to inside (corresponding to $\mathrm{p}=0.1,0.05$ ) represent the trends or differences of

960 the vertical components significant at the $90 \%$ and $95 \%$ confidence levels, respectively. 